\title{
“Bisphosphonates: Possible Modes of Action and Implications for Dental Implant Treatment. A Review of the Literature"
}

\section{Elliott Ballantyne*}

Dental Implantology, Bristol, United Kingdom

\begin{abstract}
Bisphosphonates (BP) have been commonly used over the past 40 years to treat osteoporosis, Pagets' disease hypercalcemia of malignancy, osteolytic lesions of multiple myeloma and bone metastases associated with breast, prostate, lung and other soft tissue tumours.

The main aims of this review are to:

1. Highlight the fundamental pharmacophysiological modes of action of both nitrogen and non-nitrogen bisphosphonates on bone

2. Explore their potential effects on oral hard and soft tissues

3. Discuss the implications of bisphosphonate therapy on dental implants, in particular their contribution to implant failure

4. Discuss the current recommendations and guidelines for dental implant therapy in patients receiving bisphosphonate therapy based on the available evidence.

Two distinct types of bisphosphonates have been classified and differentiated according to their mode of action chemical structure, potency, delivery, bioavailability, dosage and half-life. Bisphosphonates are classified as: 1) Nonnitrogen containing bisphosphonates (BP) and 2) Nitrogen containing bisphosphonates (N-BP).

27 studies met the study inclusion and exclusion criteria, with 8 retrospective studies and 2 case series studies evaluating the success rate of dental implants in patients with a history of bisphosphonate use, while the remaining 17 articles consisted of case series and case reports.

While there are shortcomings associated with many of the reported studies, there does appear to be a certain risk associated with the both implant placement and the maintanence of osseointegrated implants in patients receiving oral bisphosphonates.

A Southern Austrailian study estimated the risk of implant failure in patients receiving oral bisphosphonates to be $0.88 \%$.

Late implant failures appear to occur in patients treated with oral bisphosphonate exposure for a period $>3$ years especially in patients who have existing integrated implants, while early failures appear to occur in patients treated with bisphosphonates before or at the time of implant placement.

Although the results from these retrospective studies and case series are conflicting to some extent, they have heightened awareness of the possible complication of BRONJ and bisphosphonate related implant failure from long term bisphosphonate use, be it oral or iv-bisphosphonates.
\end{abstract}

\begin{abstract}
Abbreviations: AAOM: American Academy of Oral Medicine; AAOMS: American Association of Oral and Maxillofacial Surgeons; ABS: Australian Bureau of Statistics; ACR: American College of Rheumatology; ADA: American Dental Association; ASBMR: American Society for Bone and Mineral Research; ATP: Adenosine Triphosphate; BMD: Bone Mineral Density; BMP: Bone Morphogenetic Protein (ILG1 and ILG2); BON: Bisphosphonate-Associated Osteonecrosis; BP: Bisphosphonate; BRONJ: Bisphosphonate-related Osteonecrosis of the Jaw; C: Carbon; $\mathrm{CaCO}_{3}$ Calcium Carbonate; $\mathrm{CaPO}_{4}$ Calcium Phosphate; CT: Computed Tomography; CTX C-Terminal Telopeptide Test; DNA: Deoxyribonucleic Acid; FACT Fosamax Actonel Comparison Trial; FLEX: Fracture Intervention Trial Long-Term Extension; FOP Fibrodysplasia Ossicans Progressive; FPP: Farnesyl diphosphate; FPPS: Farnesyl Pyrophosphate Synthase; GGPP Geranylgeranyl diphosphate; GGPPS: Geranylgeranyl Pyrophosphate Synthase; GTP Guanosine Triphosphate; GTPase: Guanosine Triphosphatase; HBO: Hyperbaric Oxygen; HMG-CoA: 3-Hydroxy-3MethylglutarylCoenzyme A; HORIZON: Health Outcomes and Reduced Incidence with Zoledronic Acid Once Yearly; ILG1: Insulin-like Growth Factors
\end{abstract}

1; ILG2: insulin-like growth factors 2; IPP: Isopentenyl diphosphate; ISQ: Implant Stability Quotient; IV: Intravenous; Mg: Milligrams; Mm: Millimetres; N-BP: Nitrogen-containing bisphosphonate; NHL: Non-Hodgkin's Lymphoma; O: Oxygen; ONJ: Osteonecrosis of the jaw; OPG: Osteoprotegerin; ORN: Osteoradionecrosis; P: Phosphate; P-C-P: Phosphate-Carbon-Phosphate; PPi: Inorganic Pyrophosphate;

*Corresponding author: Elliott Ballantyne, Mod Physiology, BA BDentSc (TCD), MFD RCSI, MSc Dental Implantology, Bristol, UK, E-mail: elliott.ballantyne@yahoo.com

Received January 12, 2015; Accepted January 16, 2015; Published February 15,2015

Citation: Ballantyne E (2015) "Bisphosphonates: Possible Modes of Action and Implications for Dental Implant Treatment. A Review of the Literature". J Gen Pract 3. 192. doi:10.4172/2329-9126.1000192

Copyright: (c) 2015 Ballantyne E. This is an open-access article distributed under the terms of the Creative Commons Attribution License, which permits unrestricted use, distribution, and reproduction in any medium, provided the original author and source are credited. 
RANK: Receptor Activator of Nuclear Factor $\kappa B$; RANKL: Receptor Activator of Nuclear Factor $\kappa B$ Ligand; RFA: Resonance Frequency Analysis; s-CTX: serum CTX; TNF: Tumour Necrosis Factor; VEGF: Vascular Endothelial Growth Factor

\section{Introduction}

Bisphosphonates (BP) have been commonly used over the past 40 years to treat osteoporosis, Pagets' disease, hypercalcemia of malignancy, osteolytic lesions of multiple myeloma and bone metastases associated with breast, prostate, lung and other soft tissue tumours [1-15]. They are potent osteoclast inhibitors and are considered the drug of choice for the treatment of diseases affecting bone metabolism [5,16-18]. They help to reduce skeletal-related events such as fractures and the need for radiation or stabilising operations. They prevent hypercalcemic episodes, reduce pain and therefore increase the quality of life in affected patients [19].

The two modes of administration are oral and intravenous. Intravenously administered bisphosphonates are more potent than oral bisphosphonates due to the presence of an amino group to the basic P-C-P structure and not the mode of delivery [20]. However, it should also be noted that oral bisphosphonates can also contain an amino group that increases its potency [9]. There are important structureactivity relationships involved in the effects of all bisphosphonates that need to be considered $[7,9,20]$.

Bisphosphonates are routinely in the top 100 most prescribed medications in America [21]. In 2008, an estimated 4 million women in America were taking a bisphosphonate drug [22]. It is estimated that 30 million BP prescriptions are written in America with a staggering 190 million worldwide $[3,23]$. They are ideally suited for the treatment of bone disease because of their binding affinity to bone mineral at sites of active bone metabolism [24]. According to Gutta and Louis [23], the iv-bisphosphonates, zoledronate and pamidronate are being used in over 2.5 million patients worldwide. This is largely due to osteoporosis, which alone has a prevalence of 75 million in the USA, Europe and Japan.

It is generally accepted that bisphosphonates have an effect on bone, reducing osteoclastic activity and subsequently suppressing bone remodelling and turnover [1,25-29]. Two fundamental pharmacological modes of action have been extensively discussed in the literature for both nitrogen-containing (N-BP) and non-nitrogen containing bisphosphonates [1,4,5,7,28]. More recently, however, other hypotheses have been proposed regarding the possible action of bisphosphonates on the oral mucosa, in particular the oral epithelium, fibroblasts, keratinocytes and macrophages, all of which can lead to impaired oral wound healing [30-35]. Bisphosphonate related osteonecrosis of the jaw (BRONJ) has also been found to occur as a result of ill-fitting dentures without any surgical trauma and are believed to inhibit angiogenesis leading to avascular necrosis [36-39]. These hypothesis have arisen due to the occurrence of gastrointestinal and oesophageal ulceration with oral bisphosphonate therapy [40,41].

Recently, there have been a number of reports about the adverse effects of bisphosphonates which has caused concern about the longterm safety of this class of drug $[22,42]$. This is especially important as it is believed that bisphosphonates can be retained in the skeleton longer than 10 years $[25,43]$.

With an increasing proportion of the population being prescribed oral bisphosphonates, in particular, it is inevitable that some of these patients may require or request implant therapy. Therefore the effects that these drugs may have on implant survival and success is very important. The first case of BRONJ in oral and maxillofacial surgery was only reported in 2003 and involved the failure of osseointegrated dental implants $[25,44,45]$. Although studies describing the effects of nitrogen-containing bisphosphonates on alveolar bone are numerous, the effects of this class of drug on the oral soft tissue and oral wound healing are less well studied [46,47]. It is important to distinguish between the molecular and cellular modes of action of both nonnitrogen and nitrogen containing bisphosphonates, and how these effects may contribute to the pathogenesis of bisphosphonate related osteonecrosis and other adverse effects [48-50].

\section{The main aims of this review are to:}

1. Highlight the fundamental pharmacophysiological modes of action of both nitrogen and non-nitrogen bisphosphonates on bone

2. Explore their potential effects on oral hard and soft tissues

3. Discuss the implications of bisphosphonate therapy on dental implants, in particular their contribution to implant failure

4. Discuss the current recommendations and guidelines for dental implant therapy in patients receiving bisphosphonate therapy based on the available evidence.

Successful osseointegration of dental implants is dependent upon a number of factors, especially the direct structural and functional relationship between the surface of a load bearing implant and ordered living bone [51]. The characteristic features of different implant types are not for discussion in this study, but "ordered living bone" which is constantly remodelling represents a dynamic process that reflects a fine balance between osteoclastic bone resorption and osteoblastic bone formation surrounding each implant is important [52-55].

\section{Materials and Methods}

An electronic Medline search was conducted to find relevant articles from both medical and dental literature between 1950 and $31^{\text {st }}$ December 2012, that fulfilled specifically defined inclusion and exclusion criteria.

The Cochrane Database of Systematic Reviews, the Cochrane Central Register of Controlled Trials and Embase were searched for English language studies published between 2000 and $31^{\text {st }}$ December 2012.

The literature search was completed by cross checking the references cited in all relevant identified publications to ensure that no articles were missed.

\section{Inclusion criteria}

- $\quad$ Papers were selected if the title or abstract included the following Medical Subject Headings (MeSH) and terms: Bisphosphonates, diphosphonates, avascular necrosis and osteonecrosis. These terms were used in conjunction with "dental implants", "oral implants", "implant failure", "implant survival", "modes of action", "mechanisms of action", "dental implications", "oral hard tissue", "oral soft tissue", and "osseointegration". Boolean operators "AND" and "OR" were used to control the searches under the Medical Subject Headings and terms. The operator "AND" was used to focus on two particular topics of interest eg "bisphosphonates AND dental implants", while the operator "OR" was used to broaden the search.

- There is limited literature available on bisphosphonate therapy 
and implant survival as this problem has only arisen relatively recently. Because of this it was difficult to clearly establish specific criteria for the study design.

- There is also limited literature available on the effects of bisphosphonate therapy on oral hard and soft tissues.

- Case reports, case series and reviews were also included because of limited literature on this topic.

- The studies also had to be human and written in English

\section{Exclusion criteria}

- $\quad$ Foreign language publications were excluded.

- Letters and Forums were excluded.

- Studies with patients having osteonecrosis of the jaw secondary to radiation therapy or osteoradionecrosis.

\section{Types of study}

The main difficulty with studies on this topic is obtaining a large enough prospective sample to determine the rate of failure. The statistical requirements for a study to be relevant were well explained in a recent study by Goss et al. [15]. Statistically, if an adverse event occurs at a rate of 1 in 100 and a statistical level of significance of $P=.05$ is required, then a very large study population is needed, over 10,000 patients, to achieve statistical significance.

An alternative strategy to prospective studies is to retrospectively review a large number of implant cases and determine the number with bisphosphonate-associated failure.

However, due to the relatively rare incidence of bisphosphonate related implant failure, it was anticipated that there were no randomised and/or non-randomised controlled clinical trials. Therefore retrospective case-controlled studies as well as studies based on patient registries will be included.

The heterogeneity of the studies researched, in terms of study design and outcome measure, mean that this review presents a descriptive analysis of relevant papers. A meta-analysis to compare and contrast results from different studies was not possible.

\section{Evaluation of Search Results}

The search results were evaluated initially based on reading each article. The inclusion and exclusion criteria listed dictated whether or not the articles were included in the review. Any irrelevant articles or articles not meeting the inclusion and exclusion criteria were omitted.

\section{Results}

The initial search of Medline and Embase databases, regarding bisphosphonates and dental implants, yielded a total of 37 articles which were considered for the study. On further investigation 27 studies met the study inclusion and exclusion criteria. The 10 articles that were omitted failed to meet the inclusion criteria and so were excluded from the results.

A total of 8 retrospective studies and 2 case series studies evaluated the success rate of dental implants in patients with a history of bisphosphonate use. The remaining 17 articles consisted of case series and case reports. These studies described incidences of bisphosphonate related osteonecrosis of the jaw in dental implant patients with a history of bisphosphonate use.
In addition to the Medline and Embase database searches, 2 articles were obtained from the Cochrane Library that were considered to be relevant in terms of interventions for treating osteonecrosis of the jaw bones associated with bisphosphonates. The retrospective studies are summarised in (Table 1), while the case reports are summarised in (Table 2)

A second search of the Medline and Embase databases, regarding Bisphosphonates (MeSH) in conjunction with the terms; "oral soft tissues", "oral hard tissues", "avascular necrosis", "jaw bone" and "modes/mechanisms of action" yielded a total of 51 articles when limited to English language studies that were human related.

The results of this review are presented with the molecular and cellular mechanisms of action of bisphosphonates on both bone metabolism and the oral soft tissues. This provides an explanation as to the current evidence based knowledge regarding the etiopathogenesis of bisphosphonate related osteonecrosis of the jaw (BRONJ), which is a potential complication of any oral surgical procedure, including dental implant treatment, on patients receiving bisphosphonate therapy. These hypotheses are discussed in conjunction with the fundamental physiological principles of homeostatic bone remodelling and wound healing, and their potential impact on implant survival.

\section{Bisphosphonate History}

- Bisphosphonates have been known to chemists since the mid- $19^{\text {th }}$ century, with their first synthesis in Germany in 1865 [29]. At that time their main use was in the textile, fertiliser and oil industries.

- The biological importance of bisphosphonates did not become apparent until the1960s, when Herbert Fleisch and colleagues discovered that inorganic pyrophosphates (PPi) in plasma and urine inhibited calcium phosphate dissolution and precipitation in vitro $[1,29]$.

- In 1964, studies on hypophosphatasia, a rare inherited disorder in which a lack of alkaline phosphatase is associated with mineralisation defects of the skeleton, discovered that PPi levels were elevated in urine $[1,29]$. Not only were PPi levels elevated in urine but also in plasma, confirming that alkaline phosphatase regulates circulating PPi to below critical levels that would otherwise prevent normal physiological calcification processes). [1]

- Studies by Fleisch and Russell [1,29] helped to establish the concept that PPi is the bodies own water softener that normally prevents calcification of soft tissues and regulates mineralisation.

- In vivo, this compound was found to prevent ectopic calcification while having no effect on normal mineralisation and bone resorption. Because of its failure to act when given orally and its rapid hydrolysis when given parenterally, pyrophosphate was only used therapeutically in scintigraphy and against dental calculus $[1,29]$. This led to the search for pyrophosphate analogs, known as bisphosphonates, which could not be degraded.

- In 1967, a 16 year old female with myositis ossificans progressive, a condition involving calcification of soft tissue, became the first human patient to be treated with a bisphosphonate, etidronate. Her condition was critical with the muscles in her chest calcifying causing respiratory insufficiency. She was treated with etidronate, $10 \mathrm{mg} / \mathrm{kg}$ daily, initially and then intermittently for years as was needed to treat her periodic exacerbations. Her condition continued to be controlled in this manner [1,29], Like PPi, bisphosphonates were shown to have a high affinity for bone 
Citation: Ballantyne E (2015) "Bisphosphonates: Possible Modes of Action and Implications for Dental Implant Treatment. A Review of the Literature". J Gen Pract 3: 192. doi:10.4172/2329-9126.1000192

Page 4 of 28

\begin{tabular}{|c|c|c|c|c|c|c|c|c|c|}
\hline Study/year & $\begin{array}{l}\text { Number of } \\
\text { patients } \\
\text { (test/control) }\end{array}$ & $\begin{array}{l}\text { Age range } \\
\text { (years) }\end{array}$ & $\mathrm{BP} /$ dosage & $\begin{array}{l}\text { BP intake } \\
\text { duration at } \\
\text { implant } \\
\text { placement }\end{array}$ & $\begin{array}{l}\text { Number of } \\
\text { implants } \\
\text { (test/control) }\end{array}$ & $\begin{array}{l}\text { Follow- } \\
\text { up } \\
\text { duration } \\
\text { (months) }\end{array}$ & $\begin{array}{l}\text { BRONJ } \\
\text { Number }\end{array}$ & \begin{tabular}{|} 
Success \\
rate \\
in BP group \\
$(\%)$
\end{tabular} & $\begin{array}{l}\text { Success rate } \\
\text { in control } \\
\text { group (\%) }\end{array}$ \\
\hline $\begin{array}{c}\text { Jeffcoat [42] } \\
\text { Prospective single- } \\
\text { blind } \\
\text { controlled study }\end{array}$ & $25 / 25$ & $?$ & $\begin{array}{l}\text { Alendronate } \\
\text { Risedronate }\end{array}$ & $1-4$ years & $102 / 108$ & 36 & 0 & 100 & 99.2 \\
\hline $\begin{array}{c}\text { Fugazzotto et al. } \\
\text { [181] } \\
\text { Retrospective } \\
\text { analysis }\end{array}$ & $61 /$ no control & $51-83$ & $\begin{array}{c}\text { Alendronate } \\
\text { (52 patients) } \\
70 \text { mg/week (30) } \\
35 \text { mg/week (22) } \\
\text { Risedronate } \\
\text { (9 patients) } \\
35 \mathrm{mg} / \text { week (6) } \\
70 \mathrm{mg} / \text { week (3) }\end{array}$ & $\begin{array}{l}1.25 \text { patients } \\
4-5 \text { years } \\
2.36 \text { patients } \\
3 \text { years and } \\
\text { less } \\
\text { Mean: } 3.3 \\
\text { years }\end{array}$ & $169 /$ no control & $12-24$ & $\begin{array}{c}0 \\
\text { (one case of } \\
\text { bone } \\
\text { exposure } \\
\text { not matching } \\
\text { BRONJ } \\
\text { criteria) }\end{array}$ & 100 & $\begin{array}{l}\text { No control } \\
\text { group }\end{array}$ \\
\hline $\begin{array}{l}\text { Bell and Bell [182] } \\
\text { Retrospective } \\
\text { analysis }\end{array}$ & $\begin{array}{c}42 / \text { not } \\
\text { communicated }\end{array}$ & $\begin{array}{c}\text { Not } \\
\text { communicated }\end{array}$ & $\begin{array}{c}\text { Alendronate } \\
\text { (34 patients) } \\
\text { Risedronate } \\
\text { (6 patients) } \\
\text { lbandronate } \\
\text { (2 patients) } \\
\text { doses: not } \\
\text { communicated }\end{array}$ & $\begin{array}{c}\text { Not } \\
\text { communicated }\end{array}$ & $100 / 734$ & $\begin{array}{c}4-89 \\
\text { average } \\
37\end{array}$ & 0 & 95 & 96.5 \\
\hline $\begin{array}{c}\text { Grant et al. [183] } \\
\text { Retrospective } \\
\text { analysis }\end{array}$ & \begin{tabular}{|c|}
89 patients \\
under BP \\
before implant \\
surgery/1319 \\
female \\
patients with \\
implant surgery
\end{tabular} & Mean: 67.4 & $\begin{array}{l}\text { Alendronate } \\
\text { (66 patients) } \\
\text { Risedronate } \\
\text { ( } 21 \text { patients) } \\
\text { Ibandronate } \\
\text { ( } 2 \text { patients) }\end{array}$ & 38 months & $468 / 1450$ & 48 & 0 & 99.5 & 99 \\
\hline $\begin{array}{l}\text { Kasai et al. [10] } \\
\text { Retrospective } \\
\text { analysis }\end{array}$ & 65 patients & $\begin{array}{c}\text { Not } \\
\text { communicated }\end{array}$ & Alendronate & $>3$ years & $35 / 161$ & 84.3 & 0 & 86 & 95 \\
\hline $\begin{array}{c}\text { Koka et al. } \\
{[184]} \\
\text { Retrospective }\end{array}$ & $55 / 82$ & 71 year old & Oral BP & $\begin{array}{c}\text { Equal in } \\
3 \\
\text { Groups: } \\
<36 \\
36-60 \\
>60\end{array}$ & $121 / 166$ & 18 & 0 & 99.17 & 98.19 \\
\hline $\begin{array}{l}\text { Martin et al. } \\
\text { [11] } \\
\text { Case Series }\end{array}$ & $16 / 589$ & 70 years old & Alendronate/oral & 38 months & $44 /$ no controls & NA & 0 & $\begin{array}{l}41(26 \\
\text { implants } \\
\text { failed) }\end{array}$ & 0 \\
\hline $\begin{array}{c}\text { Zahid et al } \\
\text { Retrospective }\end{array}$ & $26 / 300$ & 56 years old & NA & 14-192 months & $51 / 661$ & 26 & 0 & 94.11 & 97.1 \\
\hline $\begin{array}{l}\text { Yip et al. [14] } \\
\text { Retrospective }\end{array}$ & $114 / 223$ & 40 years + & $\begin{array}{c}\text { Alendronate/ } \\
\text { Risendronate } \\
\text { Oral BP }\end{array}$ & $\begin{array}{l}>3 \text { years } \\
<7 \text { years }\end{array}$ & $490 / 691$ & 6 years & 0 & $\begin{array}{c}66.7 \\
(163 / 490 \\
\text { Implants } \\
\text { Failed })\end{array}$ & $\begin{array}{c}100 \text { (controls } \\
\text { had no } \\
\text { failures) }\end{array}$ \\
\hline $\begin{array}{l}\text { Memon et al. [13] } \\
\text { Retrospective }\end{array}$ & $100 / 100$ & $\begin{array}{c}66 \pm 9 \text { years }(\text { test }) \\
63 \pm 9 \\
\text { years }(\text { control) }\end{array}$ & $\begin{array}{c}72 \text { patients taking } \\
\text { Alendronate, } 23 \\
\text { taking risendronate, } \\
5 \text { taking } \\
\text { ibandronate }\end{array}$ & $\begin{array}{c}20 \text { patients }<1 \text { year, } \\
19 \text { patients } 1-3 \\
\text { years, } 15 \text { patients } \\
>3 \text { years; } 46 \\
\text { unknown }\end{array}$ & $153 / 132$ & $\begin{array}{c}\text { 4-6 } \\
\text { months }\end{array}$ & 0 & $\begin{array}{l}93.5(10 \\
\text { implants } \\
\text { failed })\end{array}$ & $\begin{array}{c}95.5(6 \\
\text { implants } \\
\text { failed })\end{array}$ \\
\hline
\end{tabular}

Table 1: Prospective and retrospective studies evaluating the success rate of dental implant placement in patients with a history of bisphosphonate therapy.

mineral, prevent the formation and aggregation of calcium phosphate crystals but were able to be administered orally [29].

- $\quad$ Early studies indicated that bisphosphonates may also be able to inhibit the dissolution of hydroxyapatite crystals, which lead to studies on the inhibition of bone resorption $[7,1]$.

- Research carried out at the Davos laboratories, Switzerland, discovered the potential application of bisphosphonates with respect to bone turnover $[1,7,20,29]$. In 1970-80s, etidronate (Didronel ${ }^{\circ}$ ) became approved for the treatment of Pagets' disease of bone, the prevention and treatment of heterotropic ossification due to total hip replacement or spinal cord injury and the intravenous treatment of hypercalcemia of malignancy.
- In the mid-1980s, research on bisphosphonates concentrated solely on the effects of newly synthesised bisphosphonates on the inhibition of bone resorption. However, it was not until the 1990s, that the true role of the nitrogen atom, in terms of potency, was elucidated [29].

\section{Classification of Bisphosphonates}

Two distinct types of bisphosphonates have been classified and differentiated according to their mode of action, chemical structure, potency, delivery, bioavailability, dosage and half-life $[4,5,7,9]$.

Bisphosphonates are classified as:

1) Non-nitrogen containing bisphosphonates (BP) 
Citation: Ballantyne E (2015) "Bisphosphonates: Possible Modes of Action and Implications for Dental Implant Treatment. A Review of the Literature". J Gen Pract 3: 192. doi:10.4172/2329-9126.1000192

Page 5 of 28

\begin{tabular}{|c|c|c|c|c|c|c|c|c|c|}
\hline Study/year & $\begin{array}{l}\text { Number of } \\
\text { patients } \\
\text { (test/control) }\end{array}$ & $\begin{array}{l}\text { Age range } \\
\text { (years) }\end{array}$ & $\mathrm{BP} /$ dosage & $\begin{array}{l}\text { BP intake } \\
\text { duration at } \\
\text { implant } \\
\text { placement }\end{array}$ & $\begin{array}{c}\text { Number of } \\
\text { implants } \\
\text { (test/control) }\end{array}$ & $\begin{array}{c}\text { Duration } \\
\text { between DI } \\
\text { and BRONJ } \\
\text { (months) }\end{array}$ & $\begin{array}{l}\text { BRONJ } \\
\text { Number }\end{array}$ & $\begin{array}{l}\text { Success } \\
\text { rate } \\
\text { in BP group } \\
(\%)\end{array}$ & $\begin{array}{l}\text { Success rate } \\
\text { in control } \\
\text { group (\%) }\end{array}$ \\
\hline $\begin{array}{c}\text { Subramanian et } \\
\text { al. [99] } \\
\text { Case report }\end{array}$ & 1 female & 48 year old & Alendronate / oral & $\begin{array}{c}0, \text { patient started } 1 \\
\text { year after DI }\end{array}$ & $6 / 0$ & $\begin{array}{l}\text { DI failed after } \\
5 \text { years BP } \\
\text { therapy }\end{array}$ & NA & $\begin{array}{c}0,6 \\
\text { implants } \\
\text { failed }\end{array}$ & NA \\
\hline $\begin{array}{l}\text { Kwon et al. [160] } \\
\text { Case report }\end{array}$ & $\begin{array}{l}17 \text { female } \\
\text { patients } \\
2 \text { male } \\
\text { patients }\end{array}$ & $\begin{array}{l}\text { Female mean } \\
\text { age } 66.8 \\
\text { years, } \\
\text { Male } 70.5 \\
\text { years }\end{array}$ & $\begin{array}{l}15 \text { oral BP: } \\
\text { alendronate. } \\
4 \text { iv BP }\end{array}$ & $\begin{array}{l}16 \text { patients: } 12- \\
120 \text { months } \\
3 \text { patients } 0 \\
\text { months }\end{array}$ & NA & 3-82 months & $\begin{array}{c}9 \text { mandible, } 8 \\
\text { maxilla, } 2 \text { both }\end{array}$ & $\begin{array}{l}17 \text { implants } \\
\text { removed }\end{array}$ & NA \\
\hline $\begin{array}{c}\text { Jacobsen et al. } \\
{[180]} \\
\text { Case series }\end{array}$ & $\begin{array}{l}14 / 110 \\
(7 \text { patients } \\
\text { on IV BP; } 5 \\
\text { patients on } \\
\text { oral BP) }\end{array}$ & NA & $\begin{array}{l}\text { Zoledronate / } \\
\text { risedronate / iv; } \\
\text { Alendronate/ } \\
\text { pamidronate/ } \\
\text { ibandronate/oral }\end{array}$ & $\begin{array}{l}38 \text { months for IV } \\
\text { patients } \\
50 \text { months for } \\
\text { oral BP }\end{array}$ & $\begin{array}{c}23 \text { implants } \\
\text { in } 12 \text { BRONJ } \\
\text { patients }\end{array}$ & $\begin{array}{l}\text { Mean } 20.9 \\
\text { months }\end{array}$ & $\begin{array}{c}\text { 12:posterior } \\
\text { mandible and } \\
\text { maxilla }\end{array}$ & NA & NA \\
\hline $\begin{array}{l}\text { Favia et al. } \\
\text { Case report }\end{array}$ & 1 female & 65 year old & Clodronate/iv & 60 months & $2 / 0$ & $\begin{array}{c}4 \text { months DI to } \\
\text { BRONJ }\end{array}$ & $2 /$ mandible & 0 & NA \\
\hline $\begin{array}{c}\text { Manfredi et al. } \\
{[165]} \\
\text { case series }\end{array}$ & $\begin{array}{l}3 \text { female } \\
\text { patients }\end{array}$ & $\begin{array}{c}\text { 52-89 years } \\
\text { (mean } 70.4 \\
\text { years) }\end{array}$ & $\begin{array}{l}\text { Alendronate and } \\
\text { ibandronate/oral }\end{array}$ & $36-48$ months & $3 / 0$ & $\begin{array}{l}36-48 \text { months } \\
\text { (from BP to DI) }\end{array}$ & 2/mandible & 0 & $\begin{array}{l}1 \text { maxillary } \\
\text { implant } \\
\text { success }\end{array}$ \\
\hline $\begin{array}{l}\text { Bedogni et al. } \\
\text { Case report }\end{array}$ & $\begin{array}{c}1 \text { female } \\
\text { patient }\end{array}$ & 63 years old & Alendronate/oral & 72 months & $2 / 0$ & $\begin{array}{c}24 \text { months DI to } \\
\text { BRONJ }\end{array}$ & $1 /$ mandible & $50 \%$ & NA \\
\hline $\begin{array}{l}\text { Goss et al. [15] } \\
\text { Case series }\end{array}$ & $7 / 16000$ & 62 years old & $\begin{array}{l}\text { Alendronate and } \\
\text { risendronate/oral }\end{array}$ & $3-120$ months & $19 / 28000$ & NA & $\begin{array}{l}5 / \text { maxilla and } \\
\text { mandible }\end{array}$ & $\begin{array}{l}99.11 \\
(0.89 \% \\
\text { failure })\end{array}$ & NA \\
\hline $\begin{array}{c}\text { Narongroeknawin } \\
\text { et al. } \\
\text { Case report }\end{array}$ & 1 male patient & 63 year old & Alendronate/oral & 75 months & $2 / 0$ & 1 month & 2 & 0 & NA \\
\hline $\begin{array}{c}\text { Lazarovici et al. } \\
\text { [164] } \\
\text { Case series }\end{array}$ & \begin{tabular}{|c|}
27 patients: \\
( 23 cases \\
used BP \\
before $\mathrm{DI}, 4$ \\
cases had DI \\
before BP)
\end{tabular} & 70 years old & $\begin{array}{l}\text { Alendronate/ oral; } \\
\text { pamidronate and } \\
\text { zoledronate/iv }\end{array}$ & $\begin{array}{c}23 \text { cases: } 56.7 \\
\text { months } \\
4 \text { cases: } 80 \text { from } \\
\text { DI to BP }\end{array}$ & NA & $3-43$ & $\begin{array}{l}27 / \text { maxilla and } \\
\text { mandible }\end{array}$ & NA & NA \\
\hline $\begin{array}{l}\text { Shin et al. } \\
\text { Case report }\end{array}$ & 1 female & 67 years old & Alendronate/oral & 12 months & $2 / 0$ & $\begin{array}{l}12 \text { months } \\
\text { fromDI to } \\
\text { BRONJ }\end{array}$ & $2 /$ maxilla & 100 & NA \\
\hline $\begin{array}{l}\text { Park et al. } \\
\text { Case report }\end{array}$ & 1 female & 68 years old & Alendronate/oral & 60 months & $2 / 0$ & $\begin{array}{l}12 \text { months from } \\
\text { DI to BRONJ }\end{array}$ & 2/mandible & & \\
\hline $\begin{array}{l}\text { Shiroto et al. } \\
\text { Case Report }\end{array}$ & $\begin{array}{l}1 \text { female } \\
\text { patient }\end{array}$ & 54 year old & Pamidronate & 2 years & $2 / 0$ & $\begin{array}{l}\text { DI to BRONJ } \\
72 ; \text { BP to } \\
\text { BRONJ } 24\end{array}$ & $2 /$ maxilla & 100 & 0 \\
\hline $\begin{array}{l}\text { Alons et al. } \\
\text { Case report }\end{array}$ & 1 female & 74 years old & Pamidronate/iv & 12 months & $1 / 0$ & NA & $1 /$ mandible & 100 & 0 \\
\hline $\begin{array}{l}\text { Ferrari et al. } \\
\text { Case Report }\end{array}$ & 1 male patient & 66 year old & Pamidronate /iv & $>2$ years & 6 & 12 & NA & 100 & 0 \\
\hline $\begin{array}{l}\text { Brooks et al.[186] } \\
\text { Case Report }\end{array}$ & $\begin{array}{l}1 \text { female } \\
\text { patient }\end{array}$ & 62 year old & Risedronate /oral & 3 years & $10 / 0$ & 2 & $1 /$ maxilla & 90 & 0 \\
\hline $\begin{array}{l}\text { Wang et al.[137] } \\
\text { Case Report }\end{array}$ & $\begin{array}{l}1 \text { female } \\
\text { patient }\end{array}$ & 65 year old & Alendronate /oral & $>10$ years & $5 / 0$ & 1.5 months & $2 /$ mandible & 100 & 0 \\
\hline $\begin{array}{c}\text { Starck and Epker } \\
{[185]} \\
\text { Case Report }\end{array}$ & $\begin{array}{l}1 \text { female } \\
\text { patient }\end{array}$ & 75 year old & Etidronate & 6 months & $5 / 0$ & 32 months & 5/mandible & 0 & 0 \\
\hline
\end{tabular}

Table 2: Case reports and case series of BRONJ associated with dental implant treatment.

2) Nitrogen containing bisphosphonates (N-BP) (Figure 1)

\section{Chemical Structure-Activity Relationship Bisphosphonates}

Bisphosphonates are chemical compounds that contain a P-C-P chain (Figure 2) [56]

Several different bisphosphonate compounds have been synthesised that modify the core structure of the bisphosphonate molecule (Figure 1). Two covalently bonded groups (side chains) attached to the central carbon atoms are usually referred to as $R_{1}$ and $R_{2}[7,9,28]$.
The stereochemistry of the $\mathrm{R}_{1}$ and $\mathrm{R}_{2}$ side chains and the phosphonate groups are important for the biological activity of bisphosphonates [9].

Modifications to the side chain of the central carbon atom can affect the potency of the new compound, and side chains in the $\mathrm{R}_{2}$ position that contain nitrogen greatly increase the drug potency (Table 3 and Figure 3$)[5,16,57,58]$. The potency is also increased by increasing the length of the $\mathrm{R}_{2}$ side chain attached to the central carbon atom with alkyl and amine groups, while maintaining the calcium binding affinity through the hydroxyl group in the $\mathrm{R}_{1}$ position $[5,28]$. 
<smiles>O=P(O)(O)OP(=O)(O)O</smiles>

Pyrophosphate<smiles>[R]C([R])(P(=O)([O-])[O-])P(=O)([O-])[O-]</smiles>

Bisphosphonate

\section{Non-nitrogen containing Bisphosphonates}<smiles>O=P(O)(O)C(Cl)(Cl)P(=O)(O)O</smiles>

Clodronate<smiles></smiles>

Tiludronate<smiles>CC(O)P(=O)(O)C(C)(O)P(=O)(O)O</smiles>

Etidronate

\section{Nitrogen-containing Bisphosphonates}

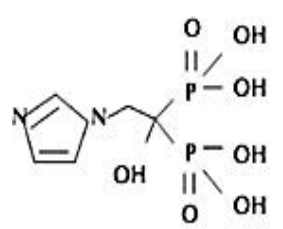

Zoledronate<smiles>CCCCCNCCC(O)(P(=O)(O)O)P(=O)(O)O</smiles>

Ibandronate<smiles>NCCCC(O)(P(=O)(O)O)P(=O)(O)O</smiles>

Alendronate

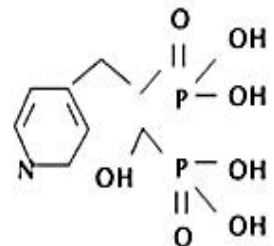

Risedronate<smiles>NCCC(O)(P(=O)(O)O)P(=O)(O)O</smiles>

Pamidronate

Figure 1: Bisphosphonates are structural analogues of pyrophosphates with a core P-C-P structure. Bisphosphonates are classified as nitrogen-containing bisphosphonates and non-nitrogen containing bisphosphonates. Adapted from Dominguez et al. [61].<smiles>O=P(O)(O)OP(=O)(O)O</smiles>

Pyrophosphate<smiles>[R]C([R])(P(=O)([O-])O)P(=O)(O)O</smiles>

\section{Bisphosphonate}

Figure 2: Pyrophosphate and basic bisphosphonate structures. Adapted from Dominguez et al. [61].

The P-C-P structure is highly resistant to hydrolysis under acidic conditions or by pyrophosphatase enzymes (Figure 3 ). The addition of carbon, oxygen, halogen, sulphur or nitrogen atoms to the central carbon atom of bisphosphonates can give rise to an

enormous range of possible structures. The binding affinity for

calcium can be increased if one of the side chains, $R_{1}$, is a hydroxyl group or amino group, because this allows the formation of a tridentate conformation that allows more effective calcium binding $[4,16,28,59,60]$.

Bisphosphonates form three dimensional structures that are capable of binding divalent metal ions such as $\mathrm{Ca}^{2+}, \mathrm{Mg}^{2+}$ and $\mathrm{Fe}^{2+}$ in a bidentate manner, by coordination of one oxygen atom from each phosphonate group with the divalent cation (Figure 3).

This high affinity of bisphosphonates for bone mineral leads to rapid clearance of the drugs from the circulation and localisation to hydroxyapatite bone mineral surfaces, which appear to localise to sites of osteoclastic activity [50].

The ability of bisphosphonates to chelate $\mathrm{Ca}^{2+}$ ions is known to be reduced at a low $\mathrm{pH}$ or highly acidic environment. This means that bisphosphonates may be released from the bone surfaces in the acidic environment of the osteoclast lacunae, giving rise to localised high concentrations of bisphosphonates that are in solution or as calcium salts $[50,61-63]$. 
Citation: Ballantyne E (2015) "Bisphosphonates: Possible Modes of Action and Implications for Dental Implant Treatment. A Review of the Literature". J Gen Pract 3: 192. doi:10.4172/2329-9126.1000192

Page 7 of 28

\begin{tabular}{|c|c|c|}
\hline Agent & $\mathrm{R}_{1}$ Side chain & $\mathrm{R}_{1}$ Side chain \\
\hline Etidronate & $-\mathrm{OH}$ & $-\mathrm{CH}_{3}$ \\
\hline Clodronate & $-\mathrm{Cl}$ & $-\mathrm{Cl}$ \\
\hline Tiludronate & $-H$ & \\
\hline Pamidronate & $-\mathrm{OH}$ & $-\mathrm{CH}_{2}-\mathrm{CH}_{2}-\mathrm{NH}_{2}$ \\
\hline Neridronate & $-\mathrm{OH}$ & $-\left(\mathrm{CH}_{2}\right)_{5}-\mathrm{NH}_{2}$ \\
\hline Olpadronate & $-\mathrm{OH}$ & $-\left(\mathrm{CH}_{2}\right)_{2} \mathrm{~N}\left(\mathrm{CH}_{3}\right)_{2}$ \\
\hline Alendronate & $-\mathrm{OH}$ & $-\left(\mathrm{CH}_{2}\right)_{3}-\mathrm{NH}_{2}$ \\
\hline Ibandronate & $-\mathrm{OH}$ & \\
\hline Residronate & $-\mathrm{OH}$ & \\
\hline Zoledronate & $-\mathrm{OH}$ & \\
\hline
\end{tabular}

Table 3: List of bisphosphonate drugs with $R_{1}$ and $R_{2}$ side chain structural attachments. Adapted from Catterall and Cawston.

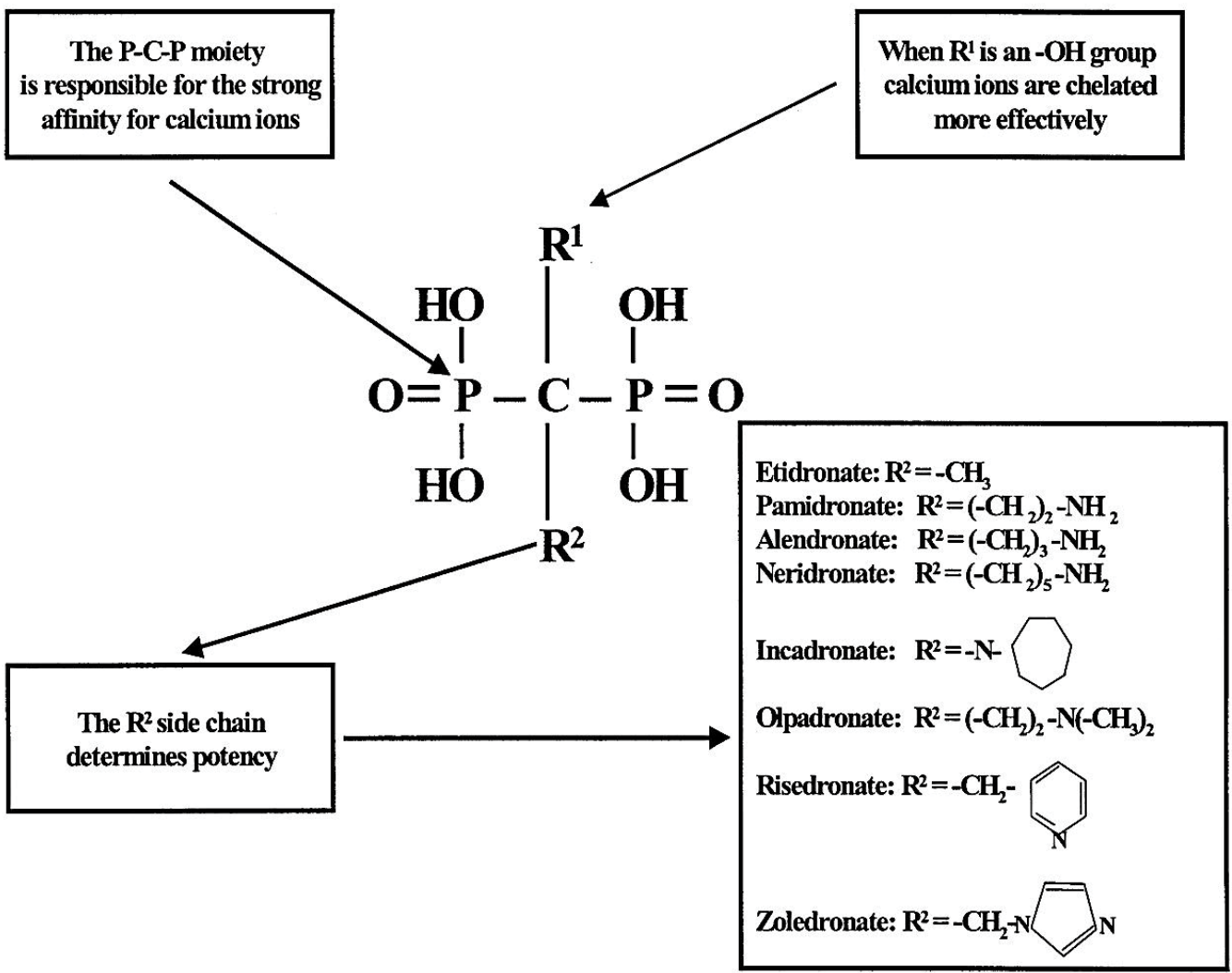

Figure 3: Bisphosphonate chemical structure-activity. The two phosphonate groups are linked to the central carbon atom by phosphoeter bonds. The carbon atom forms two additional covalent bonds, and the resulting side chains are referred to as R1 and R2. Adapted from Santini et al. [57].

Zolendronate and risendronate are the most potent bisphosphonates with a hydroxyl group in the $\mathrm{R}_{1}$ position and tertiary nitrogen within a ring structure in the $\mathrm{R}_{2}$ position [64].

\section{Clinical Applications of Bisphosphonates}

The intended primary function of bisphosphonates was the inhibition of bone resorption although its first clinical use was actually the inhibition of calcification and ossification [2,7,26,65-67], in the treatment of fibrodysplasia ossicans progressive (FOP). It was even used as an antitartar agent in toothpaste to prevent dental calculus.

Because of their high affinity for bone mineral, bisphosphonates have been used as agents for bone scanning for which they are useful 
Citation: Ballantyne E (2015) "Bisphosphonates: Possible Modes of Action and Implications for Dental Implant Treatment. A Review of the Literature". J Gen Pract 3: 192. doi:10.4172/2329-9126.1000192

Page 8 of 28

\begin{tabular}{|c|c|c|c|c|c|}
\hline $\begin{array}{l}\text { Bisphosphonate } \\
\text { (proprietary name, } \\
\text { manufacturer) }\end{array}$ & $\begin{array}{c}\text { Primary } \\
\text { Indication }\end{array}$ & $\begin{array}{c}\text { Contains } \\
\text { Nitrogen }\end{array}$ & Dose & Route & $\begin{array}{l}\text { Relative } \\
\text { Potency }\end{array}$ \\
\hline $\begin{array}{l}\text { Etidronate (Didronel, } \\
\text { Procter and Gamble) }\end{array}$ & Paget disease & No & $\begin{array}{c}300-750 \mathrm{mg} \\
\text { daily for } 6 \\
\text { months }\end{array}$ & Oral & 1 \\
\hline $\begin{array}{l}\text { Tiludronate } \\
\text { (Skelid, Sanofi-aventis) }\end{array}$ & Paget disease & No & $\begin{array}{r}400 \mathrm{mg} \\
\text { daily for } 3 \\
\text { months }\end{array}$ & Oral & 50 \\
\hline $\begin{array}{l}\text { Alendronate } \\
\text { (Fosamax, Merck) }\end{array}$ & Osteoporosis & Yes & $\begin{array}{c}10 \text { mg/day; } 70 \\
\text { mg/week }\end{array}$ & Oral & 1000 \\
\hline $\begin{array}{l}\text { Risedronate (Actonel, } \\
\text { Procter and Gamble) }\end{array}$ & Osteoporosis & Yes & $\begin{array}{c}5 \mathrm{mg} / \mathrm{day} ; 35 \\
\mathrm{mg} / \text { week }\end{array}$ & Oral & 1000 \\
\hline $\begin{array}{l}\text { Ibandronate (Boniva, } \\
\text { Roche) }\end{array}$ & Osteoporosis & Yes & $\begin{array}{l}2.5 \text { mg/day; } \\
150 \text { mg/month }\end{array}$ & Oral & 1000 \\
\hline $\begin{array}{l}\text { Pamidronate (Aredia, } \\
\text { Novartis) }\end{array}$ & Bone metastases & Yes & 90 mg/3 weeks & IV & $1000-5000$ \\
\hline $\begin{array}{l}\text { Zoledronate (Zometa, } \\
\text { Novartis) }\end{array}$ & Bone metastases & Yes & $4 \mathrm{mg} / 3$ weeks & IV & $10000+$ \\
\hline $\begin{array}{l}\text { Zoledronate (Reclast, } \\
\text { Novartis) }\end{array}$ & Osteoporosis & Yes & $5 \mathrm{mg} /$ year & IV & $10000+$ \\
\hline
\end{tabular}

Table 4: Primary indications and dosage information for all currently available bisphosphonates. Currently, there are at least 11 bisphosphonates in clinical use. Etidronate, clodronate, tiludronate, pamidronate, alendronate, ibandronate, risendronate and zolendronate being the most common with olpadronate, neridronate and minodronate rarely used (Marx et al. [18])

1. The first generation bisphosphonates, such as clodronate and etidronate, do not contain an amino group. They are metabolised to form cytotoxic adenosine triphosphate (ATP) analogs that accumulate intracellularly in osteoclasts and induce apoptosis.

2. The potent amino bisphosphonates are inhibitors of the mevalonate pathway, a biosynthetic pathway for isoprenoid proteins such as farnesyl diphosphate and geranylgeranyl diphosphate. The isoprenoid proteins are required for post-translational prenylation of the small GTPases such as RAS, Rho, and Rac. The Rho and Rac groups of proteins are responsible for cytoskeletal organisation and cell membrane ruffling and are activated through geranylgeranylation. The cytoskeleton is essential to maintain the "ruffled border", the area with which the osteoclast makes contact with bone and breaks down bone tissue. With the ruffled border compromised, the osteoclast initiates apoptosis, resulting in a decrease in bone turnover.

3. Bisphosphonates also inhibit various matrix metalloproteinases involved in cancer growth and metastasis.

4. Although BPs are also known to have antiangiogenic effects, there has been some controversy based on histological reports of osteonecrotic samples.

5. There are some reports that bisphosphonates may inhibit bone resorption by stimulating osteoblasts to produce an osteoclast-inhibitory factor.

6. Bisphosphonates are also reported to be powerful inhibitors of macrophage proliferation, cells that are of the same lineage as osteoclasts.

7. Other mechanisms include inhibition of osteoclast proton ATPase, phosphatases, and other lysosomal enzymes.

Table 5: According to Gutta and Louis [23], there are seven proposed mechanism of action of bisphosphonates.

in detecting bone metastases and other lesions [28]. They can bind to gamma-emitting technectium isotope.

In recent years, bisphosphonates have become the treatment of choice for a variety of bone diseases in which excessive osteoclast activity is an important pathological feature [29,68-71]. Bisphosphonate drugs are currently used in the medical management of osteoporosis, osteopenia, multiple myeloma, Pagets' disease, heterotopic ossification, hypercalcemia of malignancies, breast cancer therapies, and prostate cancer androgen deprivation therapy [72-74]. The iv-bisphosphonates are predominantly used for the treatment and palliative care of multiple myeloma, hypercalcemia of malignancies, breast cancer therapies and Pagets' disease, whereas patients with osteoporosis are mainly treated with oral bisphosphonates (Table 4).

\section{Mechanisms of Action}

The mechanisms of action of bisphosphonates in bone metabolism are complex (Table 5). They are believed to act on bone through several mechanisms simultaneously [5,50,61,75-82]. The reduction in osteoclastic activity occurs as a result of internalisation of bisphosphonates by the osteoclasts, causing disruption of osteoclastmediated bone resorption $[1,3,7,26-28,55,60,65]$. The decrease in osteoclast numbers is the result of the inhibition of osteoclast recruitment and acceleration of programmed cell death/apoptosis $[82,83]$. Both of these mechanisms lead to a reduction of bone resorption and a decrease in bone turnover.

\section{Cellular Mechanism}

\section{Non-nitrogen containing bisphosphonates}

First generation BPs, non-nitrogen BPs, clodronate and etidronate, closely mimic pyrophosphate [4,6-8,27-29,60]. They behave like PPi analogues being metabolically incorporated into nonhydrolyzable cytotoxic ATP analogues through the reversal of the normal actions of aminoacyl-tRNA synthases [16,58]. The resulting metabolites contain P-C-P structure in place of the $\beta, \gamma$-phosphate groups of ATP, resulting in the formation of non-hydrolysable (AppCp) metabolites. The intracellular accumulation of these metabolites within osteoclasts inhibits their function and may cause osteoclast cell death, by interfering with mitochondrial ATP-translocases. Induction of osteoclast apoptosis seems to be the primary mechanism by which the simple bisphosphonates inhibit bone resorption [26].

\section{Biochemical}

Nitrogen-containing bisphosphonates and the Mevalonate biosynthetic pathway: It is now widely accepted that nitrogen containing BPs, such as risendronate, alendronate and zoledronate, are more potent compounds $[5,29,58]$, interfering with specific metabolic pathways, notably the mevalonate biosynthetic pathway that leads to cholesterol and sterol synthesis [84] (Figure 4).

They are very effective inhibitors of bone resorption because they are internalised selectively into osteoclasts during the resorption of drug 


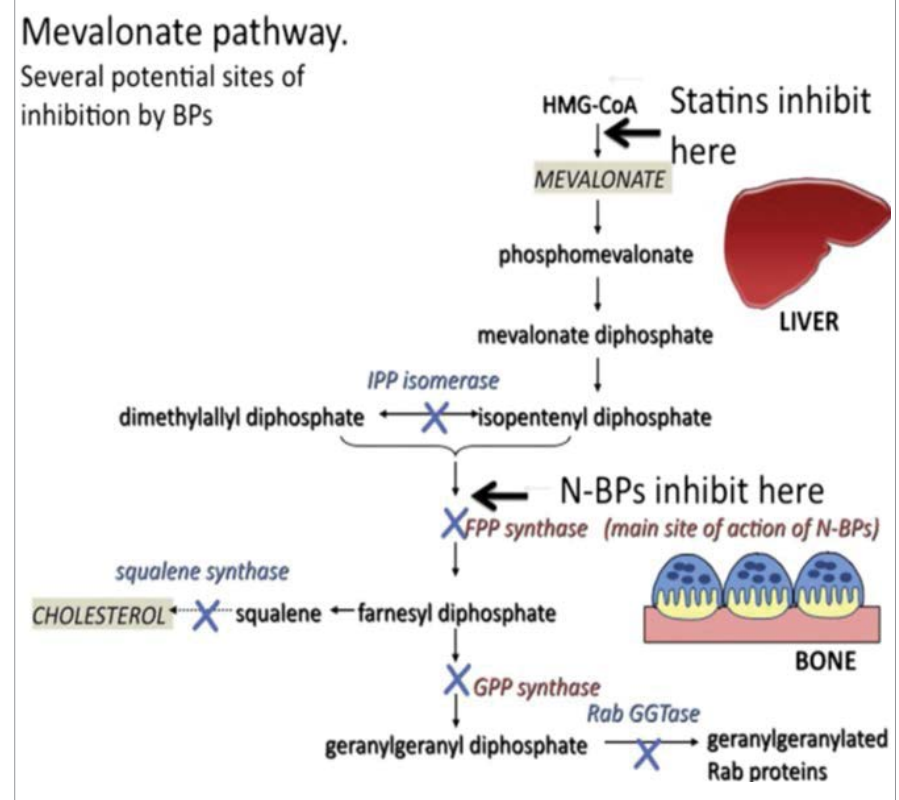

Figure 4: The Mevalonate Pathway. The mevalonate pathway is an important metabolic pathway that provides cells with essential bioactive molecules that are vital in a variety of cellular processes (Buhaescu and Izzedine [88]).

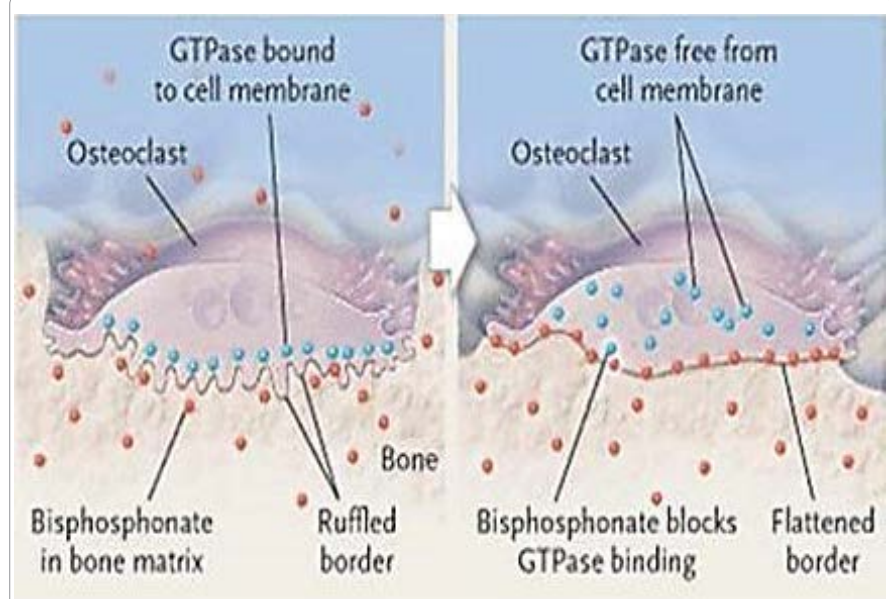

Figure 5: Illustration of the cellular changes that occur in osteoclasts as a result of the action of bisphosphonates. The fundamental importance of GTPases in osteoclastic biology was only discovered in the 90 s, following the discovery that nitrogen-containing bisphosphonate drugs inhibit bone resorption by blocking protein prenylation. Adapted from Strewler GJ in 2004.

coated bone $[85,86]$, disrupting osteoclast polarisation by preventing formation of the actin ring, disrupting vesicular trafficking and the formation of the ruffled border at the Howship lacuna resorption site (Figure 5).

The effects of N-BPs are known to be the result of disruption of protein prenylation, since these drugs mimic the structure of isoprenoid lipids such as geranyl pyrophosphate (GPP) and inhibit farnesyl pyrophosphate synthase (FPPS), a key enzyme in the mevalonate pathway of isoprenoid and cholesterol biosynthesis [7,25,28,43,87-89].

Three important isoprenoid lipids are synthesised in the mevalonate pathway:

1) isopentenyl diphosphate (IPP)
2) farnesyl diphosphate (FPP)

3) geranylgeranyl diphosphate (GGPP) [88].

FPP and GGPP are required for the prenylation of small GTPases such as RAS, Rab, Rho and Rac. Small GTPases are important signalling proteins which regulate a variety of cell processes important for osteoclast function, including cell morphology, cytoskeletal arrangements, membrane ruffling, trafficking of vesicles and apoptosis [76].

The inhibition of FPP synthase activity in osteoclasts results in the depletion of FPP and GGPP that are necessary for the prenylation of small GTPases $[85,86]$. As a result, small GTPases accumulate in the unprenyllated form and fail to localise to membrane compartments [26].

Prenylation is required for the correct function of these proteins, since the lipid prenyl group serves to anchor the proteins in cell membranes and may also participate in protein-protein interactions $[89,90]$. The effects on small GTPases signalling (Figure 5) results in disruption of cytoskeletal organisation and vesicular trafficking in osteoclasts, causing loss of the sealing zone and ruffled border and ultimately osteoclast apoptosis [16].

In particular, geranylgeranylated, rather than farnesylated, small GTPases are essential for osteoclastic function and survival, since geranylgeraniol overcomes the inhibition of osteoclast formation and bone resorption by N-BPs $[85,86]$.

Nitrogen containing bisphosphonates have no effect on cholesterol. Conversely, statins have not been shown to have any significant effect on bone clinically. The reason for this is that statins are selectively and efficiently taken up by the liver rather than bone.

\section{Long term administration of Bisphosphonates}

\section{Dose-frequency relationship}

With the long term administration of bisphosphonates, as is the case with osteoporosis, the inhibition of bone resorption reaches a steady state, rather than becoming progressively lower, even when administered continuously [65].

The total dose administered is a major determinant of their effects. This has been well studied for both zoledronate and ibandronate, in particular Importantly, in both instances, inhibition of bone resorption had been documented whether the BP was given in small frequent doses compared with larger doses given less frequently. This is the rationale behind the use of intermittent dose regimens in BP therapy.

\section{Long lasting effects of bisphosphonates}

Bisphosphonates have very long lasting effects in reducing bone turnover, which seem to be greater and more prolonged with some BPs (eg. alendronate and zolendronate) compared with others (etidronate and risendronate) [91-93].

The long duration of action has been proposed to be due to continual recycling of bisphosphonates off and back onto bone surfaces. This is supported by the fact that bisphosphonates have been observed in plasma and urine samples months after initial dosing [28].

The long retention time of bisphosphonates has potential benefits and risks. On one hand, a positive effect would be that the discontinuation of bisphosphonate therapy is associated with an anti-resorptive effect and anti-fracture protection that persists for an undefined period [93]. However, on the other hand, adverse effects that may be associated with this drug persistence may take longer to resolve. 
Two important trials, FLEX (Fracture Intervention Trial LongTerm Extension) and Horizon (Health Outcomes and Reduced Incidence with Zoledronic Acid Once Yearly) studies assessed the persistant effects of both alendronate and zoledronate respectively, after the discontinuation of these drugs.

In the FLEX trial, patients receiving oral alendronate for $>5$ years were randomised either to continue with the treatment for a total of 10 years or to stop treatment after 5 years [94]. Those who discontinued alendronate experienced a reduction in BMD without an increase in non-vertebral fractures though the risk of clinically recognised vertebral fractures was higher compared with the continuous users. In the continuous user (Alendronate group), the effect of alendronate/ placebo for 10 years was positive with 1-3\% increase in BMD, compared to a $5-10 \%$ loss in untreated women of similar age $[22,95]$. In this study markers of bone turnover gradually increased after discontinuation but remained lower than baseline even after 5 years without alendronate [22]. There was no significant difference between the alendronate group and the placebo groups [94].

In the Horizon study [94], patients were placed in groups to continue for an additional 3 years (total zoledronate exposure 6 years) or stop treatment after 3 years with zoledronate. The placebo group showed a reduction in BMD in the femoral neck, although the BMD was still higher than the pretreatment values. This showed that zoledronate was still effective even after discontinuation of treatment at 3 years [22].

\section{Doses}

Both alendronate (Fosamax) and risedronate (Actonel) have half-lifes in bone of more than 11 years [25]. Ibandronate (Boniva), another nitrogen-containing bisphosphonate, which also has a halflife of more than 11 years in bone, is unlike other bisphosphonates in that it is prescribed to be taken once per month for the treatment of osteoporosis at a dose of $150 \mathrm{mg}$ [83]. It can also be taken on a daily basis at a dose of $2.5 \mathrm{mg}$ [25] (Table 4).

Pamidronate (Aredia) is used intravenously to inhibit cancerrelated bone resorption in patients with multiple myeloma and metastatic breast cancer as well as reverse hypercalcemia of malignancy [27]. Pamidronate is administered intravenously at a dose of $90 \mathrm{mg}$ over 90 minutes every 3 to 4 weeks [83].

Zoledronate (Zometa) is the most potent intravenous nitrogencontaining bisphosphonate. It is infused over 15 minutes at an equally potent dose of $4 \mathrm{mg}$ every 3 to 4 weeks [27].

\section{Effect of bisphosphonates on the mechanical properties of bone}

The effect of bisphosphonates on the mechanical properties of the skeleton has only been discussed relatively recently $[40,58,96,97]$. This issue is important as long-lasting inhibition of bone resorption can lead to increased bone fragility and therefore, to fractures caused by an inability to replace old bone with new bone and to repair microcracks $[98,99]$.

Bisphosphonates may improve the biomechanical properties of bone, which has been found to be the case with the majority of bisphosphonates. Recent human studies have shown that alendronate actually increases vertebral and non-vertebral fractures [98]. Therefore, it is prudent to administer a dose that does not induce too great an inhibition of turnover. In treating osteoporosis, the general aim is to attain levels that correspond to those observed before the menopause i.e. $10 \mathrm{mg}$ alendronate daily [25].
Bisphosphonate doses consistent with either treatment of postmenopausal osteoporosis (daily oral alendronate) or cancer (monthly intravenous zoledronate) result in a significant suppression of bone turnover. Indeed, with daily oral alendronate, the suppression is duration dependent, with alveolar remodelling being $18 \%$ and $39 \%$ lower than vehicle treated animals after 3 and 6 months of treatment, respectively.

Longer term dosing of alendronate ( 3 years) eventually results in more dramatic reductions in turnover compared to controls $(-80 \%)$.

After just 3 months of monthly IV dosing of zoledronate, alveolar remodelling is $95 \%$ lower than controls, while after 6 months of treatment, alveolar remodelling was suppressed by $99 \%$ [97].

Shorter term treatment with higher doses of zoledronate i.e. given every 2 weeks for 3 months, suppressed alveolar turnover by $99.6 \%$ compared to controls, which were down to a rate of $0.1 \%$ year [97].

From these studies it is clear that zometa is a more potent and rapidly acting drug compared to oral alendronate dosing.

\section{Normal remodelling rates}

To put these values in perspective, Allen [40] reported that while the jaws do have higher turnover rates than other areas of the skeleton, it is not as dramatic as is sometimes implied and is even more site specific within regions of the jaws. He reported that studies involving dogs have shown that intracortical remodelling in the alveolar region of the mandible and maxilla appeared to be higher than in the basal regions.

In the alveolar region, cortical bone has a turnover rate of approximately $25 \%$ per year, while the basal mandibular turnover rate was a much lower $7 \%$ per year [100]. Within both the alveolar and basal regions of the maxilla, the remodelling rate is heterogenous, with higher rates in the anterior portion than in the posterior regions. In the mature skeleton, the alveolar mandible has higher turnover than the anterior maxilla [100].

\section{Implant Healing}

One of the shortcomings of the current available literature, identified in a recent study by Memon et al. [13] was the need for bone physiology studies to investigate the role that bisphosphonates may play in the osseointegration process.

In terms of the wound healing process around dental implants, it is important to look at both the peri-implant soft tissue healing and hard tissue healing.

Following implant placement a series of cellular and molecular processes take place in the oral mucosa adjacent to the osteotomy site, leading to the formation of peri-implant mucosa [55].

After osteotomy and implant placement, the soft tissue must be sutured in order to cover the blood clot and protect the site from bacterial ingress. This is achieved with tension free primary wound closure. The healing process of the implant site starts with the formation of the blood clot, macrophage activity, fibroblast and epithelial proliferation associated with primary osteoid formation [52].

\section{Peri-implant soft tissue healing}

The sequence of events that occur in relation to the healing of the peri-implant soft tissue are as follows [55,101-103]: 
1. Immediately following implant placement a blood coagulum separates the oral mucosa from the implant surface and alveolar bone. This blood coagulum is then infiltrated by inflammatory cells, primarily polymorphonuclear cells and is eventually replaced by a dense fibrin network.

2. The initial mucosal seal is then established by the formation of a fibrin layer at approximately day 4 after implant placement. Fibroblasts invade the fibrin network and produce collagen fibres to form connective tissue. This fibrin network is subsequently replaced with fibrous connective tissue.

3. 2 weeks after implant placement, newly formed connective tissue rich in vascular units and fibroblasts are in close contact with the implant surface.

4. The migration and proliferation of epithelial cells, occurring at 2 weeks, leads to the formation of junctional epithelium which in turn, further lengthens the contact interface between the implant surface and peri-implant mucosa. This is an important component of the protective peri-implant mucosal soft tissue seal.

5. Finally, the maturation of the peri-implant mucosa occurs between 6-12 weeks following implant placement and is characterised by the formation of a mature epithelial barrier, and organisation and alignment of collagen fibres. This keratinised oral epithelial barrier provides protection from the mechanical forces of mastication, restorative procedures and oral hygiene.

\section{Peri-implant hard tissue healing}

Osseointegration: Mavrogenis et al. [101] described the skeletal response to implant placement in different stages beginning with hematoma formation and mesenchymal tissue development, followed by woven bone formation through the intramembranous pathway, and finally lamellar bone formation on the spicules of woven bone. The placement of dental implants into the prepared osteotomy site in alveolar bone is followed by a complex cascade of events that results in osseointegration. This is defined by the "direct structural and functional relationship between ordered living bone and the load bearing surface of a dental implant" [51].

The first biological component to come into contact with an endosseous implant is blood. Blood cells including red cells, platelets, and inflammatory cells such as polymorphonuclear granulocytes and monocytes migrate from capillaries, and into the tissue surrounding the implant. The blood cells at the implant interface are activated and release cytokines and other soluble, growth and differentiation factors [52].

Initial interactions of blood cells with the implant influence clot formation. Platelets undergo morphological and biochemical changes as a response to the foreign surface including adhesion, spreading, aggregation, and intracellular biochemical changes such as induction of phosphotyrosine, increase in intracellular calcium, and hydrolysis of phospholipids [52].

The peripheral part of the implant threads engage the recipient bone and provide primary mechanical stability during the early phases of healing. The inner parts of the threads have been found to make limited or no contact with the adjacent recipient bone bed [103]. Depending on the implant design and the implant-alveolar bone interface, this space becomes occupied with a fibrin coagulum containing erythrocytes, polymorphonuclear neutrophils and few macrophages.
The fibrin coagulum is infiltrated by vascular units, originating from the adjacent recipient alveolar bone and periosteum, and fibroblast-like cells which result in the formation of granulation tissue [102].

After 1 week of wound healing, the bone debris fragments that are devoid of viable osteocytes are visible immediately laterally to the implant thread pitch [55]. Osteoclasts migrate to these sites and bone fragments undergo a process of osteoclastic resorption and remodelling, leading to their incorporation into newly formed woven bone [103].

Simultaneously, the blood coagulum and granulation tissue are replaced with a provisional connective tissue matrix containing large amounts of fibroblast-like mesenchymal cells. Some of these cells line up parallel along the implant surface and start to form collagen fibre bundles, while other fibroblast-like mesenchymal cells differentiate into osteoblasts that deposit a collagen fibre matrix that subsequently mineralises. Newly synthesised collagen fibrils are randomly distributed around sprouting vascular structures [52].

The formed fibrin matrix acts as a scaffold (osteoconduction) for the migration of osteogenic cells and eventually the differentiation (osteoinduction) of these cells in the healing space between the implant surface and the adjacent alveolar bone [101].

The second healing phase is the formation of new bone at the junction between the pre-existing bone and the implant. Osteoconduction relies on the recruitment and migration of osteogenic cells to the implant surface [102]. Newly formed woven bone extends from the wall of old lamellar bone in the direction of the implant surface and is known as distance osteogenesis [101]. In distance osteogenesis the recipient bone bed provides osteogenic cells that secrete a collagen-containing bone matrix. This bone matrix grows and mineralises, and gradually advances toward the implant surface. Conversely, in contact osteogenesis, osteogenic cells of perivascular connective tissue origin, migrate to the implant surface, differentiate and secrete a granular, afibrillar organic matrix that provides nucleation sites for mineralisation [101].

Wound healing progresses with marked woven bone formation and maturation in such a way that after 4 weeks of healing, the newly formed woven bone extends from the cut of the bone bed into the implant surface occupying close to $30 \%$ of the space [103]. The newly produced woven bone consists of trabeculae that are characterised by large areas of mineralised matrix and contain numerous osteocytes located in large lacunae.

Osteogenic cells form osteoid tissue and new trabecular bone that eventually remodels into lamellar bone in direct contact with most of the implant surface (osseointegration) [101].

The third healing phase of bone remodelling $[82,104,105]$, involves renewal of the bone and its contact to the implant surface. During the process of remodelling, the newly deposited woven bone is gradually remodelled and replaced over the course of 1-3 months by lamellar bone containing bone marrow adipocytes, blood vessels, collagen fibres and some leukocytes. Osteoblasts are observed at the implantbone interface, while osteocytes are regularly observed within the newly formed bone and extend cellular processes through canaliculi to adjacent osteocytes, vascular elements and directly onto the boneimplant interface.

As the volume occupied by the mineralised tissue increases from the early and late phases of healing, the volume occupied by the lining osteoblasts and fibroblast-like mesenchymal cells decreases. Increases in tissue mineralisation occurring over the course of healing are 


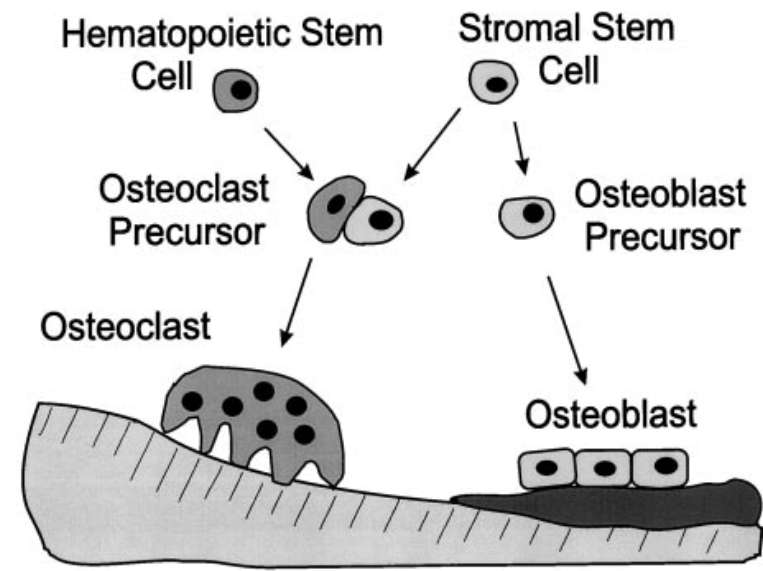

Figure 6: The differentiation pathway for both osteoclasts and osteoblasts is illustrated above. The precursor mesenchymal or stromal stem cell for osteoblasts is pluripotent and can differentiate into adipocytes or marrow support cells. Osteoblasts can be buried as osteocytes, remain in the bone as surface lining cells, or undergo apoptosis. (Adapted from Raisz [104].

accompanied by the rises in bone to implant contact, which allows for the functional loading of implants.

Bone modelling and remodelling [82], continues at a slow rate over the first year of implant placement and contributes to higher implant resistance to shear forces. This continuous process of bone modelling and remodelling is regulated by the local mechanical stress, as loading regulates proliferation and differentiation of osteoblasts and the bone healing process.

Given that bisphosphonates significantly reduce bone turnover, there is a possibility that patients taking bisphosphonates may have problems with integration occurring during the osteoconductive phase or, if the implants are already successfully integrated, the reduced bone remodelling and bone turnover may result in a potential for loss of integration [15].

\section{Bone remodelling}

As the therapeutic action of bisphosphonates is predominantly based on its effects on osteoclasts, it is important to understand the role of osteoclasts in normal homeostatic bone remodelling [105], which as we have seen, is also involved in the maintenance of osseointegration.

Bone remodelling involves a series of highly regulated steps that depend on the interactions of two cell lineages [53]:

1) Mesenchymal osteoblastic lineage (Figure 6)

2) Hematopoietic osteoclastic lineage

Remodelling cycle: There are a number of key stages in the remodelling cycle [54,82,104-107]:

1. Quiescence/activation: quiescent bone i.e. not undergoing remodelling, initiates the process of remodelling following activation, with separation of the lining cells to expose the bone and the recruitment of osteoclast precursor cells. This initial activation stage involves the interaction of osteoclast and osteoblast precursor cell, which, in turn leads to differentiation, migration and fusion of the large multinucleated, motile osteoclasts which attach to the mineralised bone surface. The attachment of osteoclasts to bone may require specific changes in the so-called "lining cells" on the bone surface, which can contract and release proteolytic enzymes to uncover a mineralised surface.

2. Resorption: this represents a period of increased osteoclastic activity, regulated by local cytokines and hormones. They initiate resorption by the secretion of hydrogen ions and lysosomal enzymes, especially Cathepsin K and Matrixmetalloproteinases (MMP), which can degrade all of the components of bone matrix, including collagen, at a low $\mathrm{pH}$. Osteoclasts are the only cells of the body able to degrade extracellular bone matrix, a process which is required for bone morphogenesis during development, for the continual repair of microdamage and the adaptation of bone to mechanical load. Osteoclastic resorption produces irregular scalloped cavities on the trabecular bone surface called Howship lacunae or cylindrical Haversian canals in cortical bone.

3. Formation: it is during this stage of the remodelling cycle that new bone is formed by osteoblast production of organic matrix and control of mineralisation. At the end of each cycle of bone remodelling new osteon is created. The maintenance of bone mass throughout the process is achieved through coupling the termination of resorption and the initiation of formation. This is under the control of proteinases and growth factors [82].

Osteoclastic bone resorption: Resorption requires certain cellular activities:

1. Migration of osteoclast to the resorption site

2. Osteoclast attachment to bone

3. Polarisation and formation of new membrane domains

4. Dissolution of hydroxyapatite

5. Degradation of organic matrix

6. Removal of degradation products from the resorption lacunae

7. Apoptosis of the osteoclasts or their return to the nonresorbing stage

Through their actions on the mevalonate pathway, nitrogen containing bisphosphonates have been shown to have direct effects on osteoclasts that regulate a variety of cellular processes important for osteoclast function, including cell morphology, cytoskeletal arrangements, loss of the sealing zone and membrane ruffling, trafficking of vesicles and apoptosis [16].

Once activated to resorb, osteoclasts reorganise their membrane into four distinct and unique regions [89].

Sealing zone

1) Ruffled border

2) The basolateral domain

3) The functional secretory domain

\section{1) Sealing zone}

This is the site where the osteoclast attaches tightly to the bone matrix, and is formed by densely packed specific actin-rich adhesion structures called "podosomes". This tight attachment of the osteoclast to the extracellular bone matrix seals off a compartment beneath the cell where bone degradation occurs i.e. the resorption lacunae [89]. 
Integrins are believed to play an important role in the early phases of the resorption cycle. There are four different integrins expressed in osteoclasts: $\alpha v \beta 3, \alpha v \beta 5, \alpha v \beta 1$ and $\alpha 2 \beta 1$. Av $\beta 3$ is highly expressed in osteoclasts and is found at both the plasma membrane and in various intracellular vacuoles. It is believed that this integrin could play a role in adhesion and migration of osteoclasts and in the endocytosis of resorption products. Another molecular family, known as the cadherins, are likely to be responsible for the formation of a tight seal [105].

\section{2) Ruffled border}

Following the formation of the sealing zone, polarised vesicular trafficking pathways result in the development of the membrane enclosed by the sealing zone into a highly convoluted "Ruffled border" where protons and proteases (acids and enzymes) demineralise and degrade the bone matrix. The ruffled border is a resorbing organelle, and is formed by fusion of intracellular acidic vesicles with the region of the plasma membrane facing bone. During the fusion process much of the internal membrane is transferred, and forms long, finger-like projections that penetrate the bone matrix [49].

\section{3) Basolateral domain and functional secretory domain}

The main physiological function of osteoclasts is to degrade mineralised bone matrix. This involves the dissolution of the crystalline hydroxyapatite and proteolytic cleavage of the organic matrix, which is rich in collagen. Before proteolytic enzymes can reach and degrade collagenous bone matrix, tightly packed hydroxyapatite must be dissolved. The dissolution of mineral occurs by targeted secretion of $\mathrm{HCl}$ through the ruffled border into the resorption lacuna. This is an extracellular space between the ruffled border membrane and the bone matrix, and is sealed from the extracellular fluid by the sealing zone. The low $\mathrm{pH}$ in the resorption lacuna is achieved by the action of ATP-consuming vacuolar proton pumps both at the ruffled border membrane and in intracellular vacuoles [106].

After solubilisation of the mineral phase, several proteolytic enzymes degrade the organic bone matrix. There are two major classes of proteolytic enzymes, lysosomal cysteine proteinases and matrix metallloproteinases (MMPs). The high levels of expression of both MMP-9 and cathepsin K in the resorption lacuna have suggested that these enzymes play a central role in the resorption process [105].

After matrix dissolution, the resulting degradation products are then endocytosed at the ruffled border, transported through the osteoclast cytoplasm by transcytosis and finally released at the opposite side of the cell at the site known as the functional secretory domain, where they are liberated into the extracellular space.

Once osteoclasts have completed their work of bone removal, there is a "reversal" phase during which mononuclear cells, maybe of macrophage lineage, are seen on the bone surface.

\section{Pharmacokinetics and Pharmacodynamics}

The pharmacokinetics and pharmacodynamics of bisphosphonates includes absorption, distribution, skeletal retention, elimination from the skeleton, renal excretion and inhibition of osteoclastic activity [9]. Lambrinoudaki et al. [108], found that gastrointestinal absorption of BPs was very poor and diminished further in the presence of food, with patients being advised to take the oral version of the drug on an empty stomach. Furthermore, gastrointestinal absorption ranges between 0.5 and $10 \%$ depending on the type of bisphosphonate administered.

\section{Absorption}

Bisphosphonates drugs can be administered either orally or intravenously. Oral bisphosphonates are absorbed throughout the full length of the GI tract by a mechanism of paracellular transport, with increased absorption in areas of greater surface area. Cremers et al. [109], found that there were small differences in absorption among bisphosphonates. Nitrogen containing bisphosphonates, alendronate, risendronate and ibandronate, have an absorption value $(\mathrm{F})$ of $0.7 \%$, whereas non-nitrogen containing bisphosphonates, clodronate and etidronate have a higher $\mathrm{F}$ of $2.0-2.5 \%$.

Cremers et al. [109] suggested that the low absorption of bisphosphonates decreases even further in the presence of food and calcium, magnesium or aluminium containing drinks but may increase in the presence of elevated gastric $\mathrm{pH}$. Li et al. [81], accounted for the low bioavailability of oral bisphosphonates due to the low efficiency of gastrointestinal uptake.

Li et al. [81] reported that regardless of the method of administration, $40-60 \%$ of plasma bisphosphonates are absorbed and the remainder is excreted through the kidney within 24 hours of administration.

The half-life of bisphosphonates in the circulation is quite short, ranging from thirty minutes to 2 hours. However, once they are incorporated into the bone tissue, they can persist for upto 10 years, depending on skeletal turnover [79].

\section{Distribution}

Early studies on bisphosphonate biodistribution by Mönkkönen et al. [110], with radiolabelled compounds showed that bisphosphonates are not excreted immediately by the kidneys, but are primarily taken up by the bone with the possibility that some may also be taken up by soft tissues such as the spleen, liver and kidney.

The exact mechanism by which bisphosphonates are transferred from the circulation to bone is unknown but it is generally believed that they enter the extracellular space by paracellular transport and bind to free hydroxyapatite that is available on the surface.

Binding has been shown to be weakest for the non-nitrogen containing bisphosphonates, etidronate, clodronate and tiludronate and stronger for the nitrogen-containing bisphosphonates risendronate, ibandronate, pamidronate, alendronate and zolendronate [9].

Weiss et al. studied the biodistribution of zolendronate within the different skeletal envelopes of the jaws and found that there was a higher uptake in trabecular bone and less in cortical bone.

Clinical studies by Cremers and Papapoulous [9], discovered that the amount of bisphosphonate delivered to the skeleton as a whole, showed a wide range. Patients with Pagets disease showed skeletal retention of olpadronate between $10-90 \%$ of the administered dose while the retention of pamidronate ranged between $47-74 \%$ in patients with osteoporosis, with patients with breast cancer and bone metastases showed skeletal retention ranging between $12-98 \%$. These wide ranges have been attributed to differences in renal function and pretreatment rate of bone turnover.

\section{Elimination}

Few bisphosphonates are actually metabolised. The non-nitrogen containing bisphosphonates etidronate and clodronate are metabolised intracellularly to cytotoxic ATP analogs. Bisphosphonates are excreted unchanged in urine, but a small percentage of parenterally administered 
bisphosphonates are excreted in bile. At pharmacological doses, BPs are excreted by glomerular filtration whereas at subtherapeutic levels tubular secretion of bisphosphonates is believed to occur, however this has only been shown in rodents [9].

\section{Skeletal elimination}

After bisphosphonates attach to the skeleton they are released from the hydroxyapatite during bone resorption and are taken up by osteoclasts, but they can also be taken up again by the skeleton or can be released again into the circulation. The amount of BP in the skeleton can be further embedded in the bone during continuing bone formation. It is believed that the bisphosphonates that are embedded in bone are released during future cycles of resorption, which explains the very slow and prolonged elimination of all BPs from the skeleton. This was confirmed by Black et al. [94], who found that after the initial and rapid clearance, the slow elimination of alendronate can take up to 12 years in humans. Another 10 year study by Bone et al. [91] discovered that low amounts of N-BPs were still detectable in the urine long after the initial IV infusion, with levels of bone resorption markers below baseline levels after 5 years of treatment with alendronate, followed by a 5 year placebo.

\section{Pharmacodynamics}

The development of appropriate therapeutic regimens for bisphosphonates can be determined by the action of the drug on bone resorption, which is a response that can be measured in vivo and in vitro. Indeed numerous attempts have been made in the past to assess the effects of BPs on bone resorption and bone turnover, but more recently specific biochemical markers have been used to obtain accurate information in human studies. Initial studies involved the treatment of patients with Pagets' disease, demonstrating that the early effect of BP treatment is the rapid decrease of bone resorption which is followed by a slower decrease in bone formation due to the coupling of these two processes.

The first study to determine the antiresorptive potencies of BPs specifically was the FACT study which compared the efficacy of 70 $\mathrm{mg}$ alendronate and $35 \mathrm{mg}$ risendronate administered once weekly to postmenopausal osteoporotic women. Alendronate was found to decrease the biochemical markers of bone turnover and increase the bone mineral density (BMD) significantly more than risendronate. Gasser et al. [111] found that in ovariectomised rats treated with BPs, the size and duration of the effect of the BP was dose-dependent. This means that high doses of weaker BPs (alendronate) can be as effective as low doses of very potent BPs (zolendronate) in the maintenance of the antiresorptive effect. Clinical studies have shown that the intravenous administration of a single $5 \mathrm{mg}$ dose of zolendronate to osteoporotic patients decreases bone resorption during a period of at least one year. Another study showed that a $7.5 \mathrm{mg}$ daily dose of alendronate over a 4 day period showed similar effects.

Cremers and Papapoulos [9] found that the overall effects of BPs on biochemical markers of bone resorption was dependent on a number of factors including potency of the BP, the drugs pharmacokinetics, the dosing regimens and the characteristics of the bone disease to be treated.

\section{Why Bisphosphonate Uptake is Greater in the Jaws}

While bisphosphonates are metabolically active in all bones of the body, the pathological condition of bisphosphonate related osteonecrosis of the jaw (BRONJ), has only been described in the maxilla and mandible. Several factors may contribute to this phenomenon. In general, both the maxillary and mandibular ridge mucosa are quite thin $(<5 \mathrm{~mm})[112,113]$. This compares less favourably with other bones that are covered with thicker, more durable tissues such as muscle and skin.

Dixon et al. [114] documented the remodelling rates of bone at various sites, finding that the alveolar crest remodels at a rate 10 times faster than the tibia, 5 times quicker than the inferior border of the mandible and $3-5$ times the rate of the mandible at the level of the ID canal. Marx et al. [43] postulated from this that the jaws accumulate higher concentrations of bisphosphonates because of the alveolar ridges rapid rate of remodelling.

This study by Dixon et al. [114], was also deemed to have demonstrated the importance of osteoclastic resorption/remodelling and renewal in the jaws compared with any other bone in the adult skeleton. Allen et al. [115] confirmed Dixons findings however, he further demonstrated that the remodelling rates where even more specific within different regions of the jaws.

\section{Extra Skeletal Effects of Bisphosphonates}

\section{Oral Wound Healing}

\section{Fibroblasts, keratinocytes, epithelial cells}

Oral wound healing, especially after a routine tooth extraction, occurs by secondary intention, consisting of a complicated cascade of events involving many different cell types including keratinocytes, gingival fibroblasts, alveolar osteoblasts, osteoclasts, osteocytes, endothelial cells and inflammatory cells. Critical to oral wound healing are cellular proliferation, migration and differentiation. The healing of an osseous wound around a dental implant is a coordinated and sequentially organised repair mechanism [102]. Terheyden and colleagues highlighted the importance of the cells that are involved in the healing of bone and their involvement in the process of osseointegration.

Numerous studies have examined the effects of bisphosphonates on fibroblasts, epithelial cells, and endothelium [30-32,116-118], investigated the effects of pamidronate and zoledronate, on primary human gingival fibroblasts. They used physiologically relevant levels of bisphosphonate determined by expected bone concentrations of bisphosphonates from animal studies. Gingival fibroblasts were found to be significantly more sensitive than oral keratinocytes to the inhibition of cellular proliferation when exposed to pamidronate.

Scheper et al. [30] also evaluated the effects of zoledronate on gingival fibroblast which resulted in apoptosis. However, there was a great degree of variation in methodology used by Scheper compared to Cozins' (2011) study. Scheper et al. [30] used different cell culture media, which was serum free. Cozin et al. [31] believes that this may have induced stress on cell viability resulting in apoptosis. Another relevant factor was Schepers' use of different cell lines to Cozins' (2011) study, which used primary human gingival fibroblasts. Cozin et al. [31] concluded that the mechanism of inhibition of proliferation and cellular migration by zoledronate, but not pamidronate in primary gingival fibroblasts is through the cholesterol/mevalonate pathway similar to osteoclasts.

Experiments in human gingival fibroblasts by Ravosa et al. [32], revealed that zoledronate and pamidronate treatments reduced collagen expression. Their study highlighted the importance of oral fibroblasts in oral wound repair following dental extraction, a process 
that is initiated by clotting and the formation of granulation tissue, followed by fibroblast migration into the wound with proliferation and deposition of collagen to increase the wound strength. The next step in the healing process involves fibroblast apoptosis leaving a collagen rich environment that stimulates re-epithelialisation. This provisional matrix is essential for the formation of a viable wound bed, to which epithelial cells migrate without proliferation but subsequently proliferate to generate additional migratory cells for wound epithelialisation and finally contraction of the wound surface. In 2011, Ravosa and colleagues showed that zoledronate treatment impedes oral soft tissue wound healing by blocking collagen expression by oral fibroblasts, resulting in a deficiency in collagen rich granulation tissue deposition needed for re-epithelialisation. Ravosa et al. [32] hypothesises that bisphosphonates released from bone after extraction may delay the wound healing of the oral mucosal barrier and subsequently contribute to BRONJ pathogenesis. Moreover, in studies using oral epithelial cell lines and fibroblasts, zoledronate significantly decreases proliferation and migration. Apoptosis in oral fibroblasts is enhanced following bisphosphonate treatment [32], and further studies in human gingival fibroblast and keratinocyte cell lines confirm these effects of zoledronate on proliferation and apoptosis. Studies using periodontal ligament fibroblasts also demonstrated that the less potent alendronate inhibits the viability of these cells as well.

Landsberg et al. reported that nitrogen containing bisphosphonates inhibited the growth of cultured keratinocytes, while Scheller et al. [33] found that they decreased the number of p63- positive keratinocyte progenitor cells and prevented the gingival fibroblasts from producing keratinocyte growth factor (KGF). A recent study by Ikebe [62], confimed the findings of Landsberg et al. and Scheller et al. [33], concluding with the presumption that inflammation of the jaws i.e. following a tooth extraction, releases the nitrogen containing bisphosphonate buried in bones, which in turn inhibits keratinocyte growth to worsen the exposure of bones, especially in patients with an ulcer or an injury formed on the mucosa.

Interestingly, studies using gingival and periodontal ligament fibroblasts show that free zoledronate induces apoptosis and necrosis in these cells. However, no effect is observed when these cells are treated with calcium phosphate incubated previously with zoledronate. Studies using free forms of bisphosphonates must be interpreted with caution, as the bound form of the drug is likely to be the most abundant one to be encountered by fibroblasts within the physiological context of the oral cavity.

Numerous studies have explored the effects of bisphosphonates on a variety of epithelial cells, including gastrointestinal cells, cervical epithelial cells, renal cells, prostate epithelial cells and oral mucosal cells. Kharazmi et al. [34,35], using in vitro models resembling oesophageal epithelium demonstrated that alendronate inhibited cellular function primarily by acting on the mevalonate pathway. Studies have been carried out to determine whether the dosages used in the in vitro experiments correlated to those encountered by gingival cells in patients with significant bisphosphonate exposure. Allam et al. [119], discovered that, when dogs were given similar doses of zoledranate to those administered to cancer patients, the high doses of zoledronate resulted in higher levels of apoptosis. He also found that there were lower levels of MMP-9 expression in oral epithelial cells. MMP-9 plays an important role in wound healing, and differences in expression may explain a delay in wound healing that has been observed in some of these studies.

\section{Direct toxicity to oral mucosal cells}

The direct toxic effects of bisphosphonates on oral mucosa can result in the ability of oral pathogens to pass through defective or severely damaged oral mucosa and infect the bone [120]. Clinically, gastrointestinal intolerability is one of the most recognisable side effects of oral preparations of nitrogen-containing bisphosphonates such as alendronate, risendronate and ibandronate. Indeed, they can cause oesophageal ulceration if they do not reach the stomach quick enough. While some authors believe that bisphosphonate toxicity to gastrointestinal cells is the result of inhibition of farnesyl pyrophosphate synthase (FPPS) in the mevalonate pathway [78], it is generally believed that a compromised integrity of the mucosal epithelium alone is not enough to allow uninterrupted access to the bone surface and that a local immune response must also be compromised. It has been postulated that the acidity of local tissue (reduced $\mathrm{pH}$ ) is altered by changes in the oral mucosa, periodontal disease, ill-fitting dentures, or dental surgery, thereby increasing the release of bisphosphonates to rise to potentially toxic levels $[97,98,121]$. These effects are believed to depress bone remodelling of the jaws and therefore impair wound healing.

\section{Angiogenesis and vasculogenesis}

Sufficient tissue vascularity and blood vessel formation is important for tissue homeostasis, local immunity and adequate regeneration. Bone tissue is particularily vascularised, and endothelial cells have been proven to play an essential role during bone remodelling [122] Indeed during bone healing and remodelling, an adequate vascular system is essential, with blood vessels in the canaliculi, Volkmans canals and the Haversian systems playing key roles. It is these vessels that involute, leaving bone dead and avascular in BRONJ [97,123]. Ziebart et al. [122], highlighted the importance of differentiating between angiogenesis and vasculogenesis. Angiogenesis being defined as the sprouting from pre-existing vessels of mature endothelial cells, whereas vasculogenesis is the potential creation of new primordial vessels from bone marrow derived, circulating endothelial progenitor cells [122]. In vitro and in vivo studies have demonstrated that the $\mathrm{N}-\mathrm{BP}$, zoledronate, has antiangiogenic effects. In vitro studies using human umbilical cord vascular endothelial cells (HUVEC) have shown that zoledronate dose-dependently inhibited the proliferation of HUVEC [24]. The inhibitory effect of zoledronate on endothelial cell adhesion and migration appears to be mediated by modulation of integrins $\left(\alpha_{5} \beta_{3}\right.$ and $\left.\alpha_{5} \beta_{5}\right)$ that are involved in angiogenesis. From this, another interesting coincidence is that $\alpha_{5} \beta_{3}$ integrin is also required for osteoclasts to adhere to bone and form resorption lacunae during active bone resorption. $\alpha_{5} \beta_{3}$ integrin expression also confers on tumour cells a greater propensity to metastasize to bone [24].

Wehrhan et al. [39] carried out a human study to determine the effects of zoledronate on angiogenesis and vascularisation. Several studies showed dose-dependent cytotoxicity of bisphosphonates on endothelial cells in vitro. Reduced endothelial cell proliferation and impaired migration during angiogenesis have also been described after administration of zoledronate in vitro [25].

Wehrhans' study of oral mucosal healing utilised CD31 as a marker of vascularisation. To date there is evidence of impairment of angiogenesis but no clear data exists about increased or decreased vascularisation. Wehrhan et al. (2011) showed a reduction of angiogenesis in BRONJ related oral mucoperiosteum compared to normal tissue. Some reports have described a decrease in expression of angiogenesis-inducing vascular endothelial growth factor (VEGF) 
in the oral mucosa of patients treated with bisphosphonates in the absence of osteonecrosis, despite a massive increase of VEGF in BRONJ mucosal lesions. VEGF and angiogenesis are physiologically known to be stimulated by tissue hypoxia and increased inflammation. The Wehrhan study group interpretation of these findings suggests that the increased VEGF expression is representative of the reparative potential and angiogenesis of the bisphosphonate exposed tissue. It also indicates that angiogenesis was specifically impaired in the absence of secondary inflammation and that this is the underlying mechanism of impaired vessel remodelling. The cellular mechanism behind the impairment of angiogenesis is postulated to be RANKL suppression by bisphosphonates [90].

Based on these findings it has been hypothesised that the resulting hypovascularity and hypocellularity leads to tissue hypoxia and subsequently necrosis [25].

\section{Macrophages}

Macrophages are much larger phagocytic cells which reach a peak concentration in a wound at 48-72 hours after the initial injury or trauma. They are attracted to the wound site by chemical messengers released from platelets or damaged cells and are able to survive in the more acidic wound environment at this stage of healing. Macrophages harbour a large reservoir of growth factors, such as TGF- $\beta$ and epidermal growth factor, which are important in regulating the inflammatory response, stimulating angiogenesis and enhancing the formation of granulation tissue [124].

As we know, osteoclasts differentiate from macrophage/ monocyte cell lineage and so it is plausible that nitrogen-containing bisphosphonates may have a similar effect on macrophages [62]. Activated macrophages display increased membrane ruffling, spreading, adhesion and lysosomal enzyme activity. They also develop phagolysosomes, an acidic compartment full of hydrolases. All of these characteristics resemble osteoclasts [125], Both macrophages and osteoclasts contain tartrate resistant acid phosphatase, which is a lysosomal protein that participates in bone resorption and in the inflammatory response of macrophages. Under physiological conditions, monocytes migrate to virtually all tissues of the body and differentiate into resident tissue macrophages. Infection, inflammation and tissue injury trigger a rapid recruitment of monocytes from peripheral blood to the affected area. These monocytes then differentiate into immune macrophages that drive the innate and adaptive immune responses.

Pazianas [125] stated that the detrimental effects of bisphosphonates on macrophages were well documented. Another recent study by Roelofs et al. [16], showed that nitrogen-containing bisphosphonates inhibited the production of cytokines in macrophages and monocytes. This is particularly important as both macrophages and monocytes play key roles in the immune system as antigen presenting cells. It has also been suggested that this local interference may significantly suppress the immunological reactions to make bones more susceptible to bacterial invasion and infection. These studies showed that bisphosphonates were internalised into J774 macrophages in the same way they are internalised in osteoclasts. Once they gain entry, it is believed that nitrogen-containing bisphosphonates inhibit cholesterol biosynthesis through the mevalonate pathway as previously described by Amin et al. [84].

\section{Immune system}

The acute phase reaction is a well-recognised adverse effect of nitrogen-containing bisphosphonates and causes influenza type symptoms such as fatigue, fever, chills, myalgia and arthralgia [126]. These symptoms can occur with both oral and iv-bisphosphonates. Usually the symptoms are transient and self-limiting and do not normally occur with subsequent drug administration.

Inhibition of FPP synthase by nitrogen-containing bisphosphonates causes accumulation of IPP, the metabolite immediately up-stream of FPP synthase in the mevalonate pathway by cells (most likely monocytes) in peripheral blood [49].

As IPP is a ligand for a receptor on the most common subset of $\gamma-\delta$ $\mathrm{T}$ cells in humans, the accumulation of IPP leads to activation of these $\mathrm{T}$ cells. This, in turn causes the release of TNFa, initiating an acute proinflammatory response.

\section{Adverse effects}

The adverse effects of bisphosphonate drugs has been extensively discussed and well documented in the literature $[42,65,122,125]$. In a comprehensive review discussing the adverse effects of bisphosphonate drugs, Abrahamsen [126], identified renal toxicity, acute phase reactions, gastrointestinal toxicity and osteonecrosis of the jaw as being the major side effects. These effects have resonated throughout the available literature on this topic $[122,125,127,128]$.

However in addition to these regularly occurring effects, Abrahamsen [126] also included bone, muscle and joint pain, atypical fragility fractures, atrial fibrillation, skin reactions (Steven Johnson Syndrome), adverse ocular effects (uveitis, scleritis) and hypocalcemia.

While all of these side effects are important, osteonecrosis of the jaws is of chief concern when carrying out any oral surgical procedure and while of a less frequent occurrence, the risk of BRONJ following the fabrication of conventional dentures or other mucosal borne dental prostheses is equally important.

Another interesting adverse effect of long term bisphosphonate administration, especially oral bisphosphonates, is the occurrence of atypical fragility fractures [129].

\section{Definition of Bisphosphonate Related Osteonecrosis of the Jaws}

Bisphosphonate Related Osteonecrosis of the Jaws (BRONJ) has been defined as an area of bone exposure in the maxilla-facial region that did not heal within 8 weeks after diagnosis by a health care provider, in a patient who was receiving or had been exposed to a bisphosphonate without a history of radiation therapy to the head and neck [25,36,130-135].

\section{Incidence of BRONJ}

Bisphosphonate related osteonecrosis of the jaw is more frequently, although by no means exclusively, induced by iv-bisphosphonates as opposed to oral bisphosphonates [130,136]. A study by Hoff et al. (2008) found that $16 / 1338$ patients with breast cancer $(1.2 \%)$ and $13 / 548$ patients with multiple myeloma $(2.4 \%)$ on iv-bisphosphonates developed BRONJ, while Wang et al. [137] reported incidences of BRONJ in 3.8\% with multiple myeloma, $2.5 \%$ with breast cancer and $2.9 \%$ with prostate cancer.

Borromeo et al. [123] estimated the risk of BRONJ to be $0.01-0.04 \%$ in patients with osteoporosis being treated with oral bisphosphonates which increased 9-fold to $0.09-0.34 \%$ following dental extraction. These authors also found that in cancer patients treated with iv- 
bisphosphonates, the estimated occurrence of BRONJ is low 0.88$1.15 \%$, however this increases to $6.7-9.1 \%$ following extraction. Another recent Southern Australian study (Goss et al. [15] estimated the risk of implant failure in patients receiving oral bisphosphonates to be $0.88 \%$.

Ruggiero [138] explained that current incidences of BRONJ have been difficult to ascertain accurately because of the use of nonstandardised definitions, inconsistencies in case recognition and reporting, as well as being based on retrospective studies with limited sample sizes. In the 2009 AAOMS position paper on Bisphosphonate Related Osteonecrosis of the Jaws, Ruggiero highlighted the cumulative incidence of BRONJ in malignant disease in patients receiving ivbisphosphonates as being between 0.8 and $12 \%$ [37]. For those patients exposed to oral-bisphosphonates, Ruggiero [68] found the incidence to be less at $0.7 / 100,000$ person years of exposure.

A recent study by Walter et al. [128] classified the prevalence of $\mathrm{BRONJ}$ according to the underlying reason for its prescription:

Osteoporosis $4.3 \%$

Malignancies $0.9-5.5 \%$

Breast cancer $1.2-11 \%$

Multiple Myeloma 3.0-21\%

Prostate cancer $3.0-19 \%$

\section{Risk factors for the development of BRONJ}

The aetiology of BRONJ is still unknown but it is believed to be of mulitifactorial pathogenesis related to many local and general factors including underlying medical health, suppression of bone turnover, inhibition of angiogenesis, soft tissue toxicity, genetic and infection [36-38].

Several retrospective clinical studies have identified potential risk factors associated with the development of BRONJ [98,138-148]. The most common risk factors include a history dentoalveolar trauma, duration of bisphosphonate therapy and the type of bisphosphonate prescribed.

In the majority of BRONJ cases reported to date, recent dentoalveolar trauma appears to be the most frequent and consistant risk factor $[25,138,149]$. Patients with a previous history of inflammatory dental disease (periodontal and dental abscess) have been found to be at a seven-fold increased risk of developing BRONJ [147,150].

The use of chronic steroids in conjunction with BP therapy has also been identified as a risk factor [151].

The duration of BP therapy appears to be related to the likelihood of developing BRONJ with longer treatment regimens associated with a greater risk of developing disease $[147,150]$. The more potent iv-bisphosphonates, pamidronate and zoledronate, seem to be more problematic compared to the oral bisphosphonates.

A study by Marx et al. [47] suggests that the current evidence indicates that the time over which a patient takes an oral-bisphosphonate (accumulation in bone) is the most critical factor. All the patients who developed osteonecrosis, had been taking oral bisphosphonates for more than 3 years. The data acquired by Marx et al. [47] suggests that most cases of BRONJ developed after 5 or more years of drug exposure and that the incidence and severity appeared to increase linearly with exposures over 3 years.

This pattern of osteonecrosis development is significantly different from osteonecrosis cases caused by iv-bisphosphonates which have been shown to require a mean of 9.3 months for Zometa and 14.1 months for Aredia to develop exposed bone [25].

It has been suggested that this faster development is due to the mode of drug administration, with the iv-route bypassing the low/variable gastrointestinal absorption that occurs with oral bisphosphonate administration, so that after $40 \%$ is cleared in the urine [9], the remainder of the iv dose accumulates in bone.

The rapid, high dose accumulation in bone associated with iv bisphosphonates induces apoptosis of large populations of osteoclasts but its repeated long-term dosing causes an imbalance exhausting the ability of the bone marrow to replenish the osteoclasts from the pool of osteoclast precursors. In comparison, the poor absorption of oral bisphosphonates represents a gradual accumulation in bone and may affect the osteoclasts less severely. In addition, their gradual accumulation in bone allows the bone marrow to keep pace with the loss of osteoclasts thereby delaying the onset of clinically exposed bone, reducing its severity, and allowing a recovery once the drug is discontinued.

The anatomical sites of development of BRONJ are also important. Mandibular alveolar bone has been shown to have a turnover rates 10 times that of long bones [47]. In addition the rate of turnover at the mandibular crest is twice the turnover at the mandibular canal and 3-5 times that of the bone at the inferior border of the mandible. This explains why both iv- and oral bisphosphonates can produce osteonecrosis which always begins at the alveolar bone.

A genetic predisposition to developing BRONJ has also been suggested $[127,134,138]$. This is believed to be related to the rs1934951 polymorphism mapped in cytochrome $\mathrm{P} 450-2 \mathrm{C}$ gene (CYP2C8), which may be associated with an increased risk for the development of BRONJ in patients treated with iv-bisphosphonates for multiple myeloma [152].

\section{Clinical features}

BRONJ may be an incidental finding, but it usually has a symptomatic clinical presentation, including pain, neuropathy, erythema, swelling, suppuration, tooth/implant mobility, halitosis, sinus tract formation, sequestration and possible pathologic fracture of the jaws [153].

The exposed bone is necrotic (osteonecrosis) secondary to bisphosphonate toxicity, similar to the genetic disorder of osteopetrosis.

Clinically, the disease presents as exposed alveolar bone that occurs spontaneously or becomes evident following an invasive surgical procedure such as tooth removal, periodontal surgery, apicectomy or dental implant placement.

Osteonecrosis of the jaws always originates in the alveolar bone and may extend to the basal bone or ramus in the mandible [63].

Occasionally, early subclinical radiographic signs such as sclerosis of the lamina dura, loss of the lamina dura, and/or widening of the periodontal ligament space, particularly in association with molar teeth has been observed [63]

\section{Histology of BRONJ}

The histopathological specimens obtained from patients that have been affected by BRONJ appears to be consistent among studies [37,154-160]. 


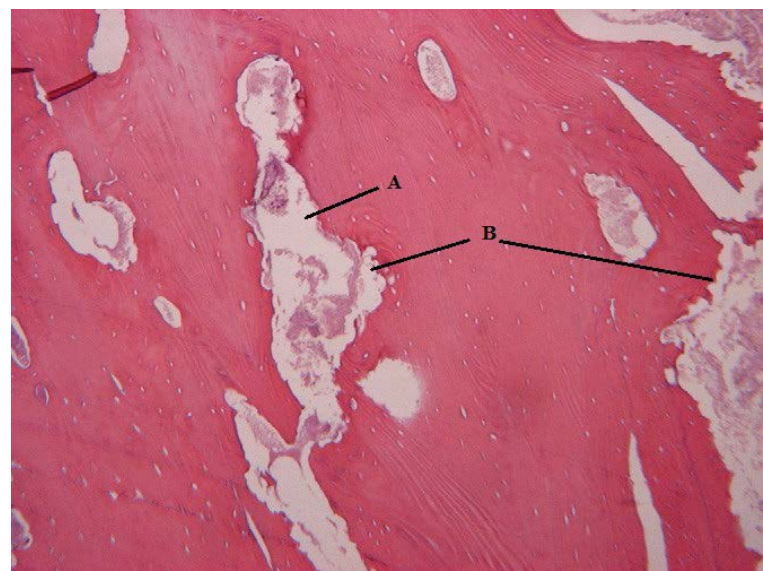

Figure 7: Histology of BRONJ affected bone. A.) Necrotic bone and empty marrow spaces, acellular, devoid of inflammatory cells seen in of bisphosphonate induced osteonecrosis. B.) Scalloping of bone edges suggestive of interrupted osteoclastic resorption at Howship's lacunae. Adapted from Marx and Tursun [159].

- Presence of Howships lacunae at various stages of formation with an absence of osteoclasts (Figure 7).

- Osteoclasts are not readily identifiable due to the bisphosphonate induced cell death - apoptosis.

- There is a lack of osteocytes in sequestered bone as it is detached from viable bone.

- The necrotic bone has a coral like quality with a thickened trabecular pattern.

- Marx and Tursun, [159] noted that the adjacent periosteum was viable, producing reactive surface bone indicating that bisphosphonates are not directly toxic to osteoblasts.

- The soft tissue associated with the bony sequestra consists of granulation tissue that contains myofibroblasts, fibroblasts and endothelial-lined channels with an inflammatory infiltrate consisting of neutrophils, plasma cells and lymphocytes.

- Microorganisms are present in the histological picture of BRONJ affected bone but it is believed that they generally play a secondary opportunistic role. The exposed bone in BRONJ being a readymade culture media for bacterial media for bacterial invasion.

- Cultures obtained from exposed necrotic bone are most often composed of commensal organisms usually Actinomyces spp. $[161,162]$.

Favia et al. [154] divided the BRONJ lesion into three major histological components:

1. Areas of soft tissue composed of active inflammatory cells with acellular necrotic debris and bone resorption

2. Areas with necrotic bony sequestra containing inflammatory cells

3. Non-necrotic bone with increased trabecular thickness.

Kwon et al. [12] found a similar histological picture present in the BRONJ lesions that affected dental implants (Figures 8 and 9). The authors proposed three distinct patterns of BRONJ associated with dental implants:

i. A "Frozen type", in which there is abundant necrotic bone around the implant with little soft tissue. ii. An "osteolytic type", with extensive osteolysis around the implant with/without sequestrum formation. Typically, there is a combination of soft tissue that is clearly inflamed with residual necrotic and viable bone.

iii. An "en block" type sequestration with the dental implant in the sequestrum. In this type of lesion there is still a considerable amount of bone-implant contact maintained. This "en block" sequestration has been seen in other studies involving the catastrophic failure of implants in bisphosphonate patients [163-165].

\section{Implant Survival}

While implant treatment has been shown to be extremely successful, it is not without its complications. The clinical success for implant treatment occurs through a series of clinical and biological steps starting with initial primary stability provided by the quantity, quality and distribution of bone within the proposed implant site [166]. Typically quoted implant survival rates are in excess of $95 \%$ over 5 years [167].

\section{Implant failure}

Implant failure can be defined as the first instance in which the performance of an implant fails to meet the criteria for success [51], (Table 6). This covers a wide variety of clinical scenarios including all symptomatic, mobile implants to implants that display greater than $0.2 \mathrm{~mm}$ of vertical bone loss after the first year of loading or bleeding pockets that are greater than $5 \mathrm{~mm}$. Implant failures can be further categorised as early or late failures, depending on whether they occur before or at abutment connection or after occlusal loading following the prosthetic restoration.

\section{Early failures}

In accordance with the definition of osseointegration, an early implant failure results from an inability to establish an intimate boneimplant contact. Several factors may contribute to this including excessive surgical trauma, infection, impaired healing, early loading and lack of biocompatibility. This loss of integration is usually clinically manifested by a peri-implant radiolucency and implant mobility. Instead of the "direct structural and functional relationship between ordered living bone and the surface" of an

implant, a fibrous connective tissue capsule is formed which inhibits the functional capacity of the bone-implant interface.

\section{Late failures}

Failures may also occur as a result of disruption of the bond between the implant and the surrounding mineralised tissues after the establishment of osseointegration. This occurs during functional loading and can be the result of overloading the supporting bone ie. occlusal overloading and chronic bacterial infection such as periimplantitis. In previous studies, early implant loss has been reported to be between $0.76-7.47 \%$, while late implant loss (5-10 years) was between $2.1-11.3 \%$ [168].

At the 2007 International Congress of Oral Implantologists in Pisa (Table 7), success, survival and failure of dental implants was the key note and a new classification system was approved [169].

\section{Discussion}

\section{Bisphosphonates and dental implants}

Review of the current literature reflects a limited, but growing, 

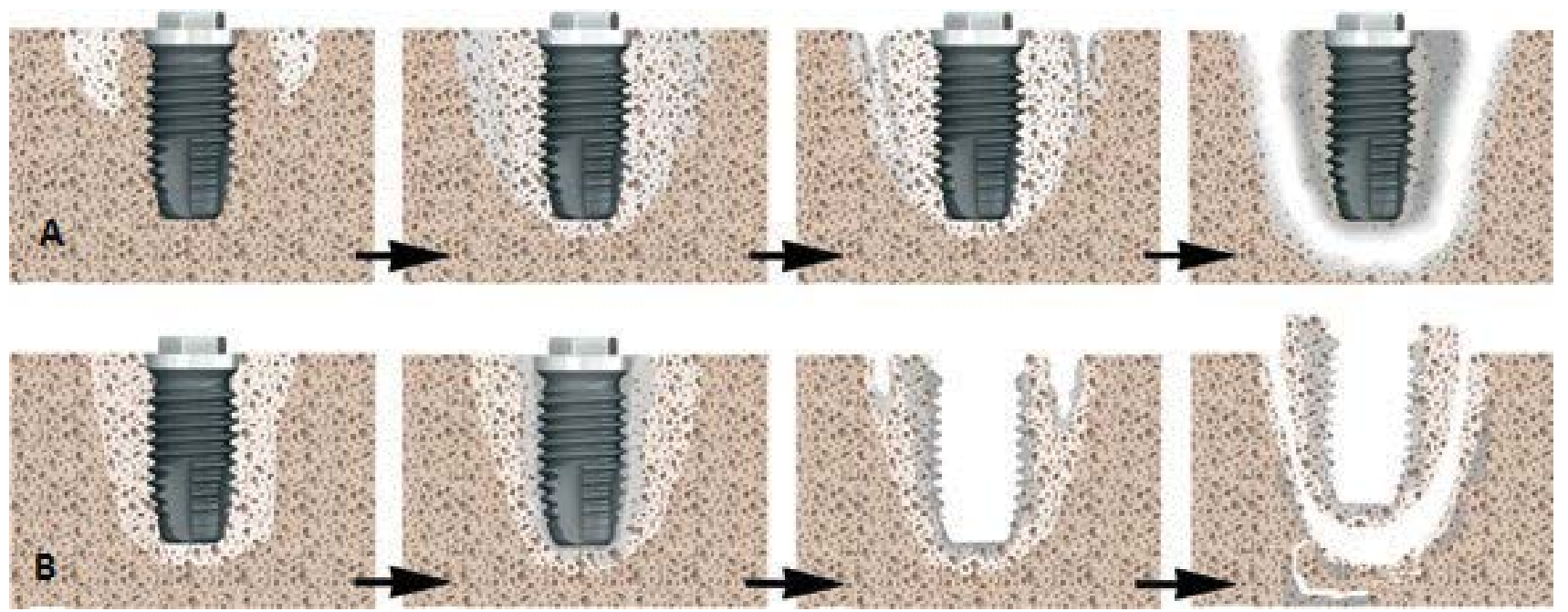

Figure 8: Proposed model of BRONJ associated with dental implant. (A) Exposed necrotic bone area became to be infected and bone destruction continues outside of implant surrounding bone and maintaining the bone-implant contact. The lesion became to be sequestrated as a block including the implant, which could be termed "en block sequestration." (B) When the alveolar bone around implant is totally necrotic and the inflammatory infiltration proceeds along with the implant surface, the implant might finally lose stability. The further osteolysis around previous implant site can result in the sequestra formation. These findings can co-exist according to the severity of the BRONJ. Adapted from Kwon et al. [12].
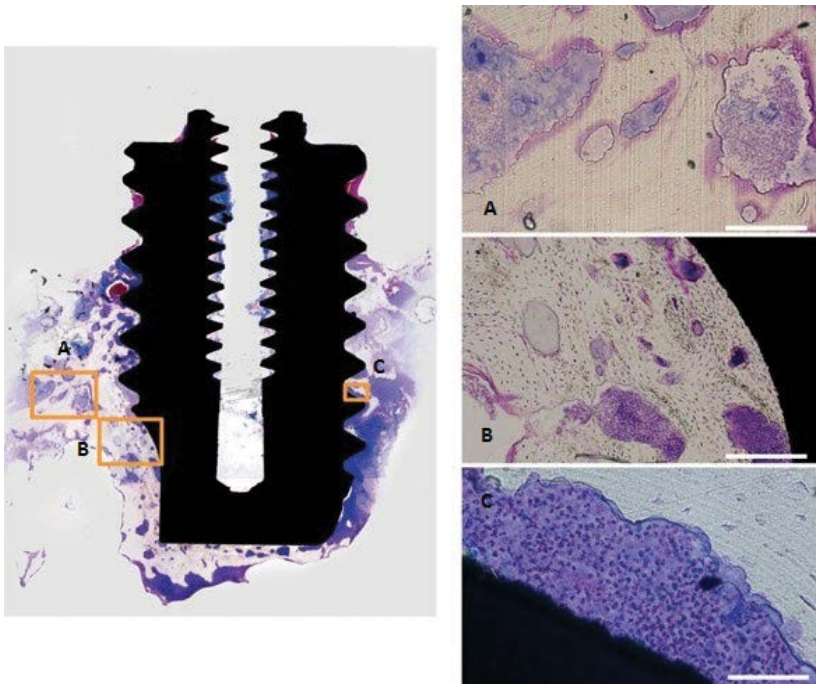

Figure 9: Histological finding of the non-decalcified section of en block sequestrated bone with an implant as a result of BRONJ. (A) Empty lacunae and colonized microorganisms within resorbed cavities (Villanueva stain). (B) Existence of osteocytes in the lacunae near the implant (Villanueva stain). (C) Higher magnification showing acute and chronic inflammatory cells such as polymorphonuclear leukocytes, lymphocytes, and plasma cells on the implant threads (Villanueva stain). Adapted from Kwon et al. [160].

Albrektsson [51] described the following factors to evaluate implant success:

1.) Immobile implant, tested clinically

2.) Absence of periapical radiolucencies

3.) After $1^{\text {st }}$ year of placement, radiographic vertical bone loss should not exceed $0.2 \mathrm{~mm}$ per annum.

4.) Absence of signs and symptoms such as pain, infection, neuropathies, paraesthesia or violation of mandibular canal leading to complications

5.) Should fulfil a minimum success rate of $85 \%$ @ years and $80 \% @ 10$ years.

Table 6: Evaluation of implant success according to Albrektsson [51]. knowledge of the relative risks to dental implant treatment in patients receiving bisphosphonate medication [139,170-179]. There have been several case reports and series that have evaluated implant failures in patients receiving intravenous bisphosphonate therapy [180], while other retrospective studies have indicated that there may be risks of osteopathology developing in patients receiving oral bisphosphonates and dental implant treatment [10-14]. While BRONJ is an important potential complication that may lead to implant failure it is important to distinguish that implant failure may also occur without the presence of any clear pathology due to a loss of osseointegration in patients being treated with bisphosphonates. This is believed to be the result of reduced bone turnover due to diminished osteoclastic activity.

The first case series of BRONJ reported a 70\% occurrence after tooth extraction or other dento-alveolar surgical procedures such as periodontal surgery and dental implant placement $[25,17,18]$. Vescovi et al. [36] highlighted a $36.2 \%$ incidence of BRONJ in a non-surgery triggered group compared to $63.8 \%$ incidence in a surgery triggered group which was found to be consistent with the findings of $[63,138]$.

Intravenous bisphosphonate therapy for underlying malignant disease seems to be a clear contraindication for the placement of dental implants, whereas implants can be placed in patients receiving oral bisphosphonates for the treatment of osteoporosis [180].

The evidence for the association between oral bisphosphonate therapy and dental implant failure appears to be mixed from the available literature related to this topic, with some studies finding an association [10-14] while other studies did not [42,181-183].

\section{Retrospective studies}

A case controlled study, Jeffcoat [42], reported the outcomes of 25 patients taking oral bisphosphonates alendronate/risedronate compared with 25 age matched controls receiving a total of 210 dental implants and found that there were no significant differences in implant survival (>99\%) and no reported cases of BRONJ.

Another research group [183] reported on 115 patients that had been treated with 468 implants during the period 1996 to 2006. Thirty 


\begin{tabular}{|c|c|c|}
\hline \multicolumn{3}{|c|}{ Health Scale for Dental Implants } \\
\hline \multicolumn{3}{|c|}{ Implant Quality Scale Clinical Conditions } \\
\hline Group & $\begin{array}{l}\text { a) } \\
\text { b) } \\
\text { c) } \\
\text { surgery } \\
\text { d) }\end{array}$ & $\begin{array}{l}\text { No pain or tenderness upon function } \\
0 \text { mobility } \\
<2 \text { mm radiographic bone loss from initial } \\
\text { No exudates history }\end{array}$ \\
\hline $\begin{array}{l}\text { II. Satisfactory } \\
\text { survival }\end{array}$ & $\begin{array}{l}\text { a) } \\
\text { b) } \\
\text { c) } \\
\text { d) }\end{array}$ & $\begin{array}{l}\text { No pain on function } \\
0 \text { mobility } \\
2-4 \text { mm radiographic bone loss } \\
\text { No exudates history }\end{array}$ \\
\hline $\begin{array}{l}\text { III. Compromised } \\
\text { survival }\end{array}$ & \multicolumn{2}{|c|}{ 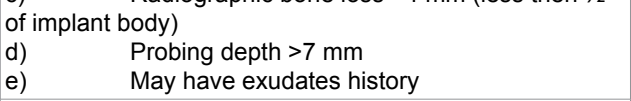 } \\
\hline $\begin{array}{l}\text { IV. Failure (clinical or } \\
\text { absolute failure) }\end{array}$ & $\begin{array}{l}\text { Any of th } \\
\text { a) } \\
\text { b) } \\
\text { c) } \\
\text { d) } \\
\text { e) }\end{array}$ & $\begin{array}{l}\text { following: } \\
\text { Pain on function } \\
\text { Mobility } \\
\text { Radiographic bone loss }>1 / 2 \text { length of implant } \\
\text { Uncontrolled exudates } \\
\text { No longer in mouth }\end{array}$ \\
\hline
\end{tabular}

Table 7: International Congress of Oral Implantologists (2007) guidelines for implant survival, success and failure.

two patients had implants placed in combination with sinus lifts. There were 2 cases of early implant failure with no reported cases of BRONJ. In 89 of the 115 patients, the implants were placed after the start of the bisphosphonate therapy. The patients were given oral alendronate, risedronate or ibandronate, 33 of them for more than 3 years. It was noted that 3 of the patients were also taking prednisolone which is a known comorbidity factor. Despite this, the reported implant survival rate was $>99 \%$.

Bell and Bell, [182] carried out a retrospective review of 101 implants placed among 42 patients who had received oral bisphosphonate therapy (alendronate, risedronate or ibandronate) for up to 11 years at the time of implant placement and found 5 implants that failed but no reported cases of BRONJ. The $5 \%$ failure rate among the bisphosphonate treated patients was comparable to the $4.5 \%$ implant failure rate among untreated patients by the same operator. There were no details given about the dosage or duration of medication or presence of any comorbidities in this study. The authors reported that implant placement was carried out in conjunction with bone augmentation in 30 patients with an implant success rate of $95 \%$.

Kasai et al. [10] carried out a retrospective chart review at the Department of Oral and Maxillofacial surgery at the University of California. Sixty five female patients over 36 years of age were treated with dental implants between 1994 and December $31^{\text {st }} 2006$. Fifteen patients were found to have osteoporosis with 11 patients being treated with an oral bisphosphonate. Three of these patients had implants that failed to integrate. The authors indicated that success rates of implants placement were $86 \%$ and $95 \%$ in case and control groups, respectively.

In 2010, Koka et al. [184] published a retrospective review that examined implant survival in 55 postmenopausal women who had received oral bisphosphonate therapy in comparison with a control group of 82 women who did not receive bisphosphonate therapy. Of the 121 implants, 120 survived in the bisphosphonate group, with no evidence of BRONJ. There were 163 of 166 implants that survived in the non-BP group. Koka and colleagues concluded that implant therapy in BP users was a "safe and predictable" procedure that did not require a drug holiday. It should be noted that their follow up period was short and their sample size was relatively small. Other authors [181-183] had similar results.

A comprehensive retrospective study with 589 patients, having received dental implants, was carried out by Martin et al. [11]. The main objectives of this study, was to investigate the frequency, location, and timing of dental implant failure in relation to cumulative bisphosphonate exposure. A total of 16 patients with failed implants were identified, all of whom were women aged $70 \pm 7$ years and had received alendronate. All of the effected patients were being treated for primary or secondary osteoporosis or as a preventative measure for osteoporotic fracture. Comorbidities did exist within this cohort of patients with 2 patients found to be current smokers and another 3 patients having stopped more than 5 years before implant placement. One patient also presented on a low dose of prednisolone. Out of a total of 44 implants, 6 were placed in the anterior maxilla, 15 in the posterior maxilla, 6 in the anterior mandible and 17 in the posterior mandible.

A total of 26 implants were found to have failed, with some failing as early as 4 years and as late as 11 years after placement. Eight patients (12 implants) had failures in the maxilla ( 3 anterior implants, 9 posterior implants). Nine patients (14 implants) had failures in the mandible (5 anterior, 9 posterior). Martin and colleagues (2010), reported that early failures were experienced by 8 patients ( 8 implants), whereas late failures ( $>1$ year after placement) occurred in 10 patients ( 18 implants).

In terms of the duration of bisphosphonate treatment at the time of implant placement, Martin et al. [11] noted that among the 10 patients (18 implants) with late implant failures, 4 patients ( $10 \mathrm{implants}$ ) had their implants placed and osseointegrated before starting bisphosphonate therapy. Interestingly, half of these implants were found to have failed during the course of bisphosphonate treatment. Four patients experienced late failures of 2 or more implants. Out of the 26 implants that failed, 7 failed in 6 patients with a mean bisphosphonate treatment duration $<3$ years, whereas 19 implants failed with 3 or more years of bisphosphonate exposure.

As with the majority of other studies on this topic, there are several limitations with this study [11]. Firstly, among the 44 implants, 10 different brands of implant were placed and all of the 16 patients had their implants placed by different operators. Secondly, there was a lack of control population and an absence of the total denominator of implants placed. Unfortunately, while being very informative and interesting, this study does not address potential differences in outcomes by implant manufacturer type, operator experience or patient risk subgroups but it does suggest that implant failure patterns in bisphosphonate-treated patients, the impact of bisphosphonate therapy on implant osseointegration and long term success is an important area for future investigation.

Recently, Yip et al. [14] carried out a large, university hospital based, case controlled retrospective study between 1997 and December 2004 on patients attending the Department of Periodontology and Dentistry at New York University College of Dentistry. The aim of this study was to investigate the association between the use of oral bisphosphonates and dental implant failure, and to examine whether this association differed by implant length and location. Yip and colleagues, discovered that during this period a total of 9701 implants were placed in the department with $55 \%$ being placed in women, and on further analysis that the implants were clustered in 1460 women aged $40+$ years.

This study clearly defined implant failure from the outset as "failure of the implant to osseointegrate or an implant that had become mobile at any time during the observation period and required removal". 
Failure was based on clinical and radiographic criteria. A total of 114 women aged $40+$, who had their first implant failure were identified. The control group consisted of 223 patients in which no implant failures occurred.

A total of 1181 implants had been placed between the case and control groups, 490 and 691 implants respectively with a mean follow up time of 6.03 years. There were 163 implant failures with higher percentage of failure occurring in the anterior maxilla $(22.7 \%)$ and the posterior mandible $(30.06 \%)$. A lower percentage of anterior mandibular implants failed (11.04\%). These findings are consistent with the findings of other studies $[10,182]$ that have reported a greater number of implant failures occurring in the maxilla of women who had received oral bisphosphonates before implant placement, but is different from the study of Martin et al. 2010 who found the numbers of implant failures in the maxilla and mandible to be similar.

A positive outcome of the study was that the authors discovered that among the implant-related and local factors, implant length, diameter and location appeared to contribute significantly towards implant failure. There was a higher percentage of failure of short $(<10$ $\mathrm{mm}$ ) implants (41.10\%) compared to short implant survival $(27.85 \%)$. A significantly greater percentage of wide diameter $(>4.5-5.5 \mathrm{~mm})$ implants failed (25.15\%) compared to survival (13.20\%).

This study clearly identifies that there is a risk of dental implant failure associated with oral bisphosphonate therapy in postmenopausal women. There were however, limitations that were also identified by Yip and colleagues (2012). These limitations included the fact the duration of bisphosphonate therapy could not be completely ascertained from the chart review. There was also a lack of confidence in patient self-reported medical and behavioural histories. As in other studies there is no measure of operator experience or mention of implant manufacturer or implant type.

Similar to Yip et al. Memon et al. $[13,14]$ carried out a retrospective chart review, from four different clinics, to compare the early success rate of dental implants in patients taking oral bisphosphonates at the time of implant placement with those patients who had never been exposed to bisphosphonates. This study group also examined the changes in crestal bone levels around the effected implants.

A retrospective chart review revealed 100 women (153 implants) who were receiving bisphosphonate therapy at the time of implant placement and 100 women (132 implants) who had never received bisphosphonates. The design of this study was very comprehensive and early implant success was clearly defined. Comorbidities and implant distribution were clearly identified within the study design. In order to control for possible surgical variability (operator experience and environment) associated with the different clinics, a similar number of patients were randomly selected from each clinic for the control group. Intra-examiner variability was calibrated by repeated measurements of a random sample of six patients over several days and a correlation coefficient of 0.93 was obtained for these two sets of data, indicating a high degree of examiner consistency and reproducibility.

A total of 10/153 implants were found to have failed to integrate at the time of stage-two surgery/abutment connection giving a success rate of $93.5 \%$. In comparison, $6 / 132$ implants failed to integrate at the same stage in the control group giving a success rate of $95.5 \%$. There were no statistically significant differences between the test and control groups in terms of crestal bone levels.

\section{Case Series and Case Reports}

The earliest case report, by Starck and Epker [185], involved a woman who developed extensive osteolysis surrounding 5 anterior mandibular implants nearly 3 years after implant placement and 6 months after starting treatment with etidronate, an oral bisphosphonate. The outcome of this case involved the removal of all 5 implants.

Until 2003, there had been few reported cases of delayed healing, implant loss, and/or osteonecrosis after implant placement among patients receiving oral bisphosphonate drugs [11]. In 2005, Marx et al reported 30 consecutive patients with BRONJ following oral bisphosphonate therapy, including 2 cases that occurred after dental implants. Wang et al. [137] also reported a woman who had received alendronate for 10 years and developed "unexplained clinical signs of bone necrosis after routine dental implant placement".

Brooks et al. [186] published a case of protracted bone graft healing (>18 months) requiring several debridements and removal of bony sequestra in a patient with chronic risedronate exposure, in whom 1 of 10 maxillary implants were lost.

Goss et al. [15] used a different approach to collect data. They contacted all the general and specialist dentists that were placing implants in South Austrailia over a 10 year period until December 2007. A total of 46 practitioners were identified with approximately 28,000 implants placed in 16,000 patients. They identified 7 cases of oral-bisphosphonate-associated implant failure, with 3 cases of failure of osseointegration and 4 cases of successful implants losing integration after being placed on oral bisphosphonates. This was the first study to focus on early and late implant failures that were related to bisphosphonate treatment. A failure rate of $0.89 \%$ was calculated based on the assumption that $5 \%$ of the patients were taking an oral bisphosphonate.

Submaramian et al. [99] defined early and delayed implant failure in patients receiving oral bisphosphonates, as a lack of adequate healing and failure to maintain osseointegration, respectively. The authors reported delayed, synchronous and rapid failure of multiple successfully integrated implants in the anterior mandible, in the absence of excessive occlusal overloading or poor oral hygiene, in a patient receiving long-term oral bisphosphonate therapy.

This study creates an interesting parallel between atypical implant failure and atypical osteoporotic fractures that can be seen with long term bisphosphonate therapy. The authors highlight characteristics common to both conditions including:

a) An inability to tolerate normal/low forces such as occlusal loading from a complete maxillary denture which the authors found comparable to low-impact hip fractures

b) Uncharacteristic pattern of implant failure comparable to rare, catastrophic fracture of the femur

c) Common association with long term oral bisphosphonate therapy.

\section{Recommendations}

In 2006, the American Association of Oral Maxillofacial Surgeons (AAOMS) released a position paper that proposed a staging system (Table 8 ) to aid in the prognosis and treatment of the symptoms of BRONJ [18].

In the most severe cases of BONJ, affected patients may experience large amounts of tooth loss and bone damage frequently resulting in 
Citation: Ballantyne E (2015) "Bisphosphonates: Possible Modes of Action and Implications for Dental Implant Treatment. A Review of the Literature". J Gen Pract 3: 192. doi:10.4172/2329-9126.1000192

Page 22 of 28

\begin{tabular}{|c|c|}
\hline Ruggiero classification (2006) & Proposal for new classification (2008-2009) \\
\hline $\begin{array}{c}\text { Stage 1: } \\
\text { Exposed bone necrosis without symptoms }\end{array}$ & $\begin{array}{l}\text { Stage } 1 \text { : } \\
\text { Exposed bone necrosis or small ulceration without exposed bone necrosis, but } \\
\text { without symptoms }\end{array}$ \\
\hline $\begin{array}{c}\text { Stage } 2 \text { : } \\
\text { Exposed bone necrosis with symptoms }\end{array}$ & $\begin{array}{l}\text { Stage 2a: } \\
\begin{array}{c}\text { Exposed bone necrosis or a small oral fistula without exposed bone necrosis, but } \\
\text { with symptoms controlled with medical treatment } \\
\text { Stage } 2 \mathrm{~b} \text { : }\end{array} \\
\begin{array}{c}\text { Exposed bone necrosis or a small fistula without exposed bone necrosis, but with } \\
\text { symptoms not controlled with medical treatment }\end{array}\end{array}$ \\
\hline $\begin{array}{c}\text { Stage } 3 \text { : } \\
\text { Jaw factures, skin fistula, osteolysis extending to the inferior border }\end{array}$ & $\begin{array}{c}\text { Stage } 3 \text { : } \\
\text { Jaw fractures, skin fistula, osteolysis extending to the inferior border }\end{array}$ \\
\hline
\end{tabular}

Table 8: Comparison of the Ruggiero classification system with that of the Oral Oncology working group of Bagan et al., [136].

\section{BRONJ Staging}

At risk category No apparent necrotic bone in patients who have been treated with either oral or IV bisphosphonates

Stage $\mathbf{0}$ No clinical evidence of necrotic bone, but non-specific clinical findings and symptoms

Stage 1 Exposed and necrotic bone in patients who are asymptomatic and have no evidence of infection

Stage 2 Exposed and necrotic bone associated with infection as evidenced by pain and erythema in the region of the exposed bone with or without purulent drainage

Stage 3 Exposed and necrotic bone in patients with pain, infection, and one or more of the following: exposed and necrotic bone extending beyond the region of alveolar bone,(i.e., inferior border and ramus in the mandible, maxillary sinus and zygoma in the maxilla) resulting in pathologic fracture, extra-oral fistula, oral antral/ oral nasal communication, or osteolysis extending to the inferior border of the mandible of sinus floor

Table 9: BRONJ staging and treatment strategies. Adapted from the AAOMS position paper by Ruggiero et al.

extensive resection sometimes leaving insufficient healthy bone for successful implant placement or denture retention.

The classification system was modified based upon proposals submitted by Bagan et al [136] (Tables 8 and 9) may have advantage in that it provides further direction for management when compared to classification [137].

\section{Prevention}

There is a general consensus among various international associations, AAOMS, ADA, CAOMS, that a comprehensive oral examination and establishment of oral health is undertaken before initiating intravenous or oral bisphosphonate therapy $[17,18,123,187,188]$. The American Academy of Oral Medicine (2005) outlined basic preventative measures and management protocol for patients with established BRONJ.

The American Dental Association's Expert Panel (2006) established comprehensive recommendations for patients' undergoing bisphosphonate treatment and was the first organisation to devise specific recommendations for dental implant placement, periodontal and oral surgical procedures. These recommendations were subsequently updated and modified in 2008 to include recommendations for orthodontic treatment, the use of collagen breakdown testing (CTX) and drug holidays [189].

The American Society for Bone and Mineral Research [137] summarized its recommendations which were based on the reason and type of bisphosphonate therapy the patients were using. Surprisingly, this organization specifically recommended that a dental examination was not deemed necessary before commencing bisphosphonate therapy unless the underlying disease is malignancy.

\section{Treatment Strategies}

ent indicated

- Systemic management, including the use of pain medication and antibiotics

- Antibacterial mouth rinse

- Clinical follow-up on a quarterly basis

Patient education and review of indications for continued bisphosphonate therapy

- Symptomatic treatment with oral antibiotics

- Oral antibacterial mouth rinse

- Pain control

- Superficial debridement to relieve soft tissue irritation

- Antibacterial mouth rinse

- Antibiotic therapy and pain control

- Surgical debridement/resection for longer term palliation of infection
In 2009, the AAOMS formed a Task Force on BisphosphonateRelated Osteonecrosis of the Jaws lead by Salvatore Ruggiero (Table 9). This position paper was an updated version of the guidelines devised by Ruggiero et al. [131] and established treatment strategies according to the various stages of BRONJ development (Table 8). With respect to oral surgical treatment, this position paper clearly states that for patients who have been taking oral bisphosphonates for less than 3 years with no clinical risk factors, no alteration or delay in proposed surgery is required. It included procedures routinely carried out by oral and maxillofacial surgeons, periodontists and other dental practitioners [18]. Importantly, Ruggiero et al. [18] recommends that if dental implants have been placed, then informed consent should be obtained from the patient outlining the risk of possible future implant failure and the risk of development of BRONJ.

The basic recommendations of these organisations can be summarised as follows:

1. Patients should be dentally fit and attend a dental practitioner for a full dental examination if they have not done so in the last 6 months.

2. Existing conditions and other potential risk factors for osteonecrosis of the jaw should be identified.

3. Should dental problems be present, then every effort should be made to have them treated prior to the onset of bisphosphonate treatment.

4. If extractions are required, then bisphosphonate treatment should be delayed until the extraction site has healed fully (14-21 days). If the underlying medical condition will not permit the delay of bisphosphonate treatment, then dental treatment will have to be carried at a suitable time after the initiation of bisphosphonate 
1. Perioperative oral antibiotics for 7 days, starting 48 hours before surgical intervention. All patients received the oral antibiotics amoxicillin and clavulanic acid (875 $\mathrm{mg} / 125 \mathrm{mg}$ ) every 12 hours or, in cases of penicillin allergy, clindamycin $600 \mathrm{mg}$ every 8 hours.

2. The surgical procedures were routinely performed under local anesthesia.

3. After surgery, all bony edges around the region of surgery were strictly smoothened by use of a surgical bur.

4. For cases of tooth extraction, a vestibular mucoperiostal flap was raised and the periosteum on the mucoperiostal flap was incised. After appropriate mobilization of the mucoperiostal flap, wound seal was achieved by use of horizontal mattress sutures and single knots to adapt the edges of epithelium, using absorbable suture material (Vicryl 4/0; Ethicon, Norderstedt, Germany). Patients were followed up 1, 2, 4, and 12 weeks and 6 and 12 months postsurgery.

5. Antiseptic mouth rinsing, using $1 \%$ peroxide and Kamillan (Pharma Wernigerode, Wernigerode, Germany), was prescribed 3 times a day

6. Removal of the sutures was not performed until at least 14 days after surgery.

7. Dental prostheses were removed, strictly, for at least 3 weeks postsurgery.

Table 10: Principles of oral surgery for the prevention of bisphosphonate-related osteonecrosis of the jaw adopted by the department of Oral and Maxillofacial Surgery and Facial Plastic Surgery of the University of Leipzig

treatment, with the most invasive procedures performed first as the risk of BRONJ increases with long-term use.

5. Existing dental prostheses should be assessed carefully and proposed dental prostheses carefully designed. Mucosal breakdown is the second most common reason for the development of BRONJ lesions [95].

6. Bronj is most commonly associated with procedures that stimulate bone around teeth, especially extractions, endodontic surgery, implantology, periodontal surgery. It is also associated with mucosal trauma such as those caused by ill- fitting dentures or the presence of anatomical anomalies such as mandibular or palatal tori.

7. In general, it is recommended that high-risk operative procedures be avoided especially in patients being treated with ivbisphosphonates and therefore there is a reliance on restorative and non-invasive dental treatment. In teeth that cannot be restored, endodontic treatment of the remaining roots should be considered following the removal of any residual coronal tooth structure that may be irritant to adjacent soft tissues.

8. Within the guidelines that have been suggested, elective dentoalveolar surgical procedures are considered to be an unnecessary risk and are contraindicated in patients undergoing treatment with iv-bisphosphonates.

9. Those patients receiving oral bisphosphonates appear to represent a group with a much smaller risk of developing BRONJ, however with increasing numbers of reports of cases of BRONJ in these patients it would appear that dentoalveolar surgery is a specific risk factor [146,190-194].

10. Specific guidelines related to the risks of oral bisphosphonates on dental implants have not been defined clearly by any of the guidelines other than the ADA in 2006. As we have seen in the literature there have been quite a few reports of high success rates and survival of dental implants in patients receiving oral bisphosphonates. Interpretation of these outcomes must be carefully reviewed as the nature and duration of bisphosphonate treatment are generally not clearly defined.

11. Finally, the majority of organisations agree that a safe approach is the best policy when dealing with patients being treated with oral bisphosphonates, assessing the specific risks on an individual basis with appropriate consent obtained [171].

\section{Bone markers}

Bone remodelling can be assessed through many markers of bone turnover or renewal that can be found in blood or urine. Bone formation indices include bone specific alkaline phosphatase and osteocalcin.
However, BRONJ is a problem associated with bone resorption and so markers of bone resorption include levels of pyridinolines and deoxypyridinolines, and urine or serum levels of type 1 collagen telopeptides (NTX and CTX respectively).

Serum CTX can identify changes in bone remodelling within several days to 2 weeks which is much quicker than measureable changes in $\mathrm{BMD}$. Serum CTX is used in most oral bisphosphonate research and is a standard test for bone turnover $[43,160]$.

During bone resorption, the osteoclast cleaves a specific carboxyl terminal end fragments from a cross-linking peptide in the type 1 collagen in bone which is measurable in blood and urine, CTX and NTX.

As with most laboratory tests, there are shortcomings associated with the CTX test. Serum CTX is known to be subject to circadian variation and can also be affected by fasting [63]. Marx's use of the $\mathrm{s}$-CTX to determine treatment protocols for patients being treated with oral bisphosphonates has received much criticism and the reliability of this test has been called into question $[132,160]$ due to Marxs' failure to use a control group.

\section{Drug holiday}

Currently, there is no published evidence to support or oppose the discontinuation of bisphosphonate therapy once osteonecrosis develops or before required dental surgery $[22,195]$. It has been suggested that the long half-life of bisphosphonates means that the recovery of normal osteoclast function and bone turnover after drug withdrawal may be too gradual for it to be of any significant clinical benefit to the patient [195].

Other studies concluded that patients may benefit from bisphosphonate withdrawal with reports of healing and resolution of bisphosphonate related sites of osteonecrosis after several months of cessation. It has been suggested that this is due to the removal of the antiangiogenic effect of the bisphosphonates on the soft tissues and overlying periosteum. Based upon this theory, it has been proposed that discontinuation of oral bisphosphonates for several weeks before and after dentoalveolar surgery may be warranted. However, it should be noted that until data from clinical trials are available, the optimal timing and duration of drug holidays are arbitrary and must be weighed against the risks posed by not taking the medication.

There have been several recommendations by a variety of organisations regarding the discontinuation of bisphosphonates for a period of time. The AAOMS and CAOMS suggest a drug holiday in patients taking iv-bisphosphonates who require invasive dental treatment, especially extractions. The ADA, AAOM and Spanish guidelines are somewhat more diplomatic in their recommendations, stating that while there is no evidence to support the use of drug 
holidays, evidence is emerging that a drug free period might be useful [196].

McLeod et al. [158] sensibly recommends that any decision on drug holidays should be made with careful consultation with the prescribing physician because of the risk of adverse events if the treatment is stopped.

\section{Positive effects of bisphosphonates on dental implant treatment}

Extensive research undertaken by Abtahi et al. [197] investigated whether a bisphosphonate coating could be beneficial to implant osseointegration. In a recent study, Abtahi et al. [197] showed that a bisphosphonate coating improved the fixation of dental implants in humans. They carried out a randomized double-blind study, in which fibrinogen-coated dental implants with immobilized pamidronate and ibandronate were inserted into the maxilla. The implant stability was determined by resonance frequency analysis (RFA) and implant stability quotant (ISQ) readings. Radiographic appearances were improved when compared to a control group.

The theory behind this positive effect is that once bisphosphonates are released from the surface of the coated implant, there is a localized reduction in osteoclastic activity, altering the balance of bone remodeling in favour of increased osteoblastic activity, leading to increased bone formation which in turn increases the local bone density $[197,198]$. The authors hope that this improved early fixation may reduce the rate of late implant failures and could also allow earlier loading times.

\section{Conclusions}

Most of the studies encountered, are case reports (Table 2) and case series or retrospective studies (Table 1) comprising of weak to moderate strength of evidence with most studies having small population sizes, varying treatment modalities, paucity of statistical analyses and lack of control for variables or their effect.

The results of these retrospective studies and case series appear to suggest that:

1. Bisphosphonate related implant failure appears to be more common in women than in men. This may be due to the fact that a greater proportion of the population receiving bisphosphonates tends to be post-menopausal osteoporotic women [14].

2. The majority of patients are receiving oral bisphosphonate therapy with a smaller population being treated with iv-bisphosphonates [43].

3. The duration of bisphosphonate therapy is critically important with respect to the development of BRONJ [43]. Khosla et al. [132] defined long term bisphosphonate therapy as $>3$ years. The duration of the follow up period associated with the majority of studies is limited (mean duration 34 months), which given the long half-lifes of bisphosphonates ( $>10$ years) may not give an appropriate evaluation of implant outcome. To a certain extent one might ask the question: "Is the worst yet to come?" Certainly, in recent years there does appear to be an increased number of cases arising in the literature.

4. The posterior regions of both the maxilla and mandible appear to be sites most frequently affected with respect to implant failure. Those cases that affect the posterior maxilla are possibly due to an already existing poor quality of bone which is further diminished by the reduction in bone turnover caused by bisphosphonate therapy.

5. While there are shortcomings associated with many of the reported studies, there does appear to be a certain risk associated with the both implant placement and the maintanence of osseointegrated implants in patients receiving oral bisphosphonates [10-14].

6. Late implant failures appear to occur in patients treated with oral bisphosphonate exposure for a period $>3$ years especially in patients who have existing integrated implants [10], while early failures appear to occur in patients treated with bisphosphonates before or at the time of implant placement.

7. The utility of bone turnover markers in guiding oral surgical treatment decisions is controversial as mean and median measurements noted in large study groups may not extrapolate to an individual case. Although not a definitive predictor of ONJ development, these markers may have a role in risk assessment before oral or other surgical procedures involving bone [43].

8. Osseointegration [51] remains the predominant factor/parameter in implant dentistry [199].

Although the results from these retrospective studies and case series are conflicting to some extent, they have heightened awareness of the possible complication of BRONJ and bisphosphonate related implant failure from long term bisphosphonate use, be it oral or ivbisphosphonates.

Very few studies actually give procedural guidelines on the practical aspects of oral surgical principles or implant placement in patients on oral bisphosphonate treatment. Heufelder et al. [200] outlined the principles of oral surgery for the prevention of bisphosphonaterelated osteonecrosis of the jaw adopted by the department of Oral and Maxillofacial Surgery and Facial Plastic Surgery of the University of Leipzig (Table 10).

These oral surgical principles could be considered and adapted to dental implant placement in suitable patients receiving oral bisphosphonates. In terms of an atraumatic approach, there is undoubtedly a need to explore the possibility of flapless guided implant placement in these patients. Prolonged healing times are required following surgery. Meticulous oral hygiene measures and maintenance schedules need to be inforced. Another aspect that I believe to be important in these patients is the recording of baseline levels of implant stability (ISQ) using RFA. By recording these values frequently one might be able to detect early loss of osseointegration in the absence of symptoms.

\section{References}

1. Fleisch H (2002) Development of bisphosphonates. Breast Cancer Res 4: 30-34.

2. Bornstein MM, Cionca N, Mombelli A (2009) Systemic conditions and treatments as risks for implant therapy. Int J Oral Maxillofac Implants 24 Suppl: 12-27.

3. Madrid C, Sanz M (2009) What impact do systemically administrated bisphosphonates have on oral implant therapy? A systematic review. Clin Oral Implants Res 20 Suppl 4: 87-95.

4. Rogers MJ (2003) New insights into the molecular mechanisms of action of bisphosphonates. Curr Pharm Des 9: 2643-2658.

5. Rogers MJ, Crockett JC, Coxon FP, Mönkkönen J (2011) Biochemical and molecular mechanisms of action of bisphosphonates. Bone 49: 34-41.

6. Rogers MJ, Frith JC, Luckman SP, Coxon FP, Benford HL, et al. (1999) Molecular mechanisms of action of bisphosphonates. Bone 24: 73S-79S. 
Citation: Ballantyne E (2015) "Bisphosphonates: Possible Modes of Action and Implications for Dental Implant Treatment. A Review of the Literature". J Gen Pract 3: 192. doi:10.4172/2329-9126.1000192

Page 25 of 28

7. Rogers MJ, Gordon S, Benford HL, Coxon FP Luckman SP et al. (2000) Cellular and molecular mechanisms of action of bisphosphonates. Cancer 88 2961-2978.

8. Rogers MJ, Watts DJ, Russell RG (1997) Overview of bisphosphonates. Cancer 80: 1652-1660.

9. Cremers S, Papapoulos S (2011) Pharmacology of bisphosphonates. Bone 49: $42-49$

10. Kasai T, Pogrel MA, Hossaini M (2009) The prognosis for dental implants placed in patients taking oral bisphosphonates. J Calif Dent Assoc 37: 39-42.

11. Martin DC, O'Ryan FS, Indresano AT, Bogdanos $P$, Wang $B$, et al. (2010) Characteristics of implant failures in patients with a history of oral bisphosphonate therapy. J Oral Maxillofac Surg 68: 508-514.

12. Kwon TG, Lee CO, Park JW, Choi SY, Rijal G, et al. (2014) Osteonecrosis associated with dental implants in patients undergoing bisphosphonate treatment. Clin Oral Implants Res 25: 632-640

13. Memon S, Weltman RL, Katancik JA (2012) Oral bisphosphonates: early endosseous dental implant success and crestal bone changes. A retrospective study. Int J Oral Maxillofac Implants 27: 1216-1222.

14. Yip JK, Borrell LN, Cho SC, Francisco H, Tarnow DP (2012) Association between oral bisphosphonate use and dental implant failure among middleaged women. J Clin Periodontol 39: 408-414.

15. Goss A, Bartold M, Sambrook P, Hawker P (2010) The nature and frequency of bisphosphonate-associated osteonecrosis of the jaws in dental implan patients: a South Australian case series. J Oral Maxillofac Surg 68: 337-343.

16. Roelofs AJ, Thompson K, Gordon S, Rogers MJ (2006) Molecular mechanisms of action of bisphosphonates: current status. Clin Cancer Res 12: 6222s-6230s.

17. Ruggiero SL, Carlson ER, Assael LA (2009) Comprehensive review of bisphosphonate therapy: implications for the oral and maxillofacial surgery patient. J Oral Maxillofac Surg 67: 1

18. Ruggiero SL, Dodson TB, Assael LA, Landesberg R, Marx RE, et al. (2009) American Association of Oral and Maxillofacial Surgeons position paper on bisphosphonate-related osteonecrosis of the jaw update, Aust Endod J 119-30.

19. Walter C, Klein MO, Pabst A, Al-Nawas B, Duschner H, et al. (2010) Influence of bisphosphonates on endothelial cells, fibroblasts, and osteogenic cells. Clin Oral Investig 14: 35-41.

20. Fleisch H (1998) Bisphosphonates: mechanisms of action. Endocr Rev 19: 80-100

21. Epstein MS, Ephros HD, Epstein JB (2013) Review of current literature and implications of RANKL inhibitors for oral health care providers. Oral Surg Oral Med Oral Pathol Oral Radiol 116: e437-442.

22. Ott SM (2011) What is the optimal duration of bisphosphonate therapy? Cleve Clin J Med 78: 619-630.

23. Gutta R, Louis PJ (2007) Bisphosphonates and osteonecrosis of the jaws: science and rationale. Oral Surg Oral Med Oral Pathol Oral Radiol Endod 104 186-193.

24. Green JR (2004) Bisphosphonates: preclinical review. Oncologist 9 Suppl 4 3-13.

25. Marx RE, Sawatari Y, Fortin M, Broumand V (2005) Bisphosphonateinduced exposed bone (osteonecrosis/osteopetrosis) of the jaws: risk factors, recognition, prevention, and treatment. J Oral Maxillofac Surg 63: 1567-1575.

26. Coxon FP, Thompson K, Rogers MJ (2006) Recent advances in understanding the mechanism of action of bisphosphonates. Curr Opin Pharmacol 6: 307-312.

27. Russell RG (2006) Bisphosphonates: from bench to bedside. Ann N Y Acad Sci 1068: 367-401.

28. Russell RG (2007) Bisphosphonates: mode of action and pharmacology Pediatrics 119 Suppl 2: S150-162.

29. Russell RG (2011) Bisphosphonates: the first 40 years. Bone 49: 2-19.

30. Scheper MA, Badros A, Chaisuparat R, Cullen KJ, Meiller TF (2009) Effect of zoledronic acid on oral fibroblasts and epithelial cells: a potential mechanism of bisphosphonate-associated osteonecrosis. Br J Haematol 144: 667-676.

31. Cozin M, Pinker BM, Solemani K, Zuniga JM, Dadaian SC, et al. (2011) Nove therapy to reverse the cellular effects of bisphosphonates on primary human oral fibroblasts. J Oral Maxillofac Surg 69: 2564-2578.
32. Ravosa MJ, Ning J, Liu Y, Stack MS (2011) Bisphosphonate effects on the behaviour of oral epithelial cells and oral fibroblasts. Arch Oral Biol 56: 491-498.

33. Scheller EL, Baldwin CM, Kuo S, D'Silva NJ, Feinberg SE, et al. (2011) Bisphosphonates inhibit expression of p63 by oral keratinocytes. J Dent Res 90: 894-899.

34. Kharazmi M, Persson U, Warfvinge G (2012) Pharmacovigilance of oral bisphosphonates: adverse effects manifesting in the soft tissue of the ora cavity. J Oral Maxillofac Surg 70: 2793-2797.

35. Kharazmi M, Sjöqvist K, Warfvinge G (2012) Oral ulcers, a little known adverse effect of alendronate: review of the literature. J Oral Maxillofac Surg 70: 830-836.

36. Vescovi P, Campisi G, Fusco V, Mergoni G, Manfredi M, et al. (2011) Surgerytriggered and non surgery-triggered Bisphosphonate-related Osteonecrosis of the Jaws (BRONJ): A retrospective analysis of 567 cases in an Italian multicenter study. Oral Oncol 191-4.

37. Vescovi P, Merigo E, Meleti M, Manfredi M, Guidotti R, et al. (2012) Bisphosphonates-related osteonecrosis of the jaws: a concise review of the literature and a report of a single-centre experience with 151 patients. J Oral Pathol Med 41: 214-221.

38. Vescovi P Nammour S (2010) Bisphosphonate-Related Osteonecrosis of the Jaw (BRONJ) therapy. A critical review. Minerva Stomatol 59: 181-203 204-13.

39. Wehrhan F, Stockmann P, Nkenke E, Schlegel KA, Guentsch A, et al. (2011) Differential impairment of vascularization and angiogenesis in bisphosphonateassociated osteonecrosis of the jaw-related mucoperiosteal tissue in Oral Surg Oral Med Oral Pathol Oral Radiol Endod 216-21.

40. Allen MR (2011) The effects of bisphosphonates on jaw bone remodeling, tissue properties, and extraction healing. Odontology 99: 8-17.

41. Allen MR, Burr DB (2009) The pathogenesis of bisphosphonate-related osteonecrosis of the jaw: so many hypotheses, so few data. J Oral Maxillofac Surg 67: 61-70.

42. Jeffcoat MK (2006) Safety of oral bisphosphonates: controlled studies on alveolar bone. Int J Oral Maxillofac Implants 21: 349-353.

43. Marx RE, Cillo JE Jr, Ulloa JJ (2007) Oral bisphosphonate-induced osteonecrosis: risk factors, prediction of risk using serum CTX testing, prevention, and treatment. J Oral Maxillofac Surg 65: 2397-2410.

44. Landesberg R, Cozin M, Cremers S, Woo V, Kousteni S, et al. (2008) Inhibition of oral mucosal cell wound healing by bisphosphonates. J Oral Maxillofac Surg 66: $839-847$

45. Landesberg R, Woo V, Cremers S, Cozin M, Marolt D, et al. (2011) Potential pathophysiological mechanisms in osteonecrosis of the jaw. Ann N Y Acad Sci 1218: $62-79$.

46. Kharazmi M, Persson U, Warfvinge G (2012) Pharmacovigilance of oral bisphosphonates: adverse effects manifesting in the soft tissue of the ora cavity. J Oral Maxillofac Surg 70: 2793-2797.

47. Kharazmi M, Sjöqvist K, Warfvinge G (2012) Oral ulcers, a little known adverse effect of alendronate: review of the literature. J Oral Maxillofac Surg 70: 830-836.

48. Corrado A, Santoro N, Cantatore FP (2007) Extra-skeletal effects of bisphosphonates. Joint Bone Spine 74: 32-38.

49. Baron R, Ferrari S, Russell RG (2011) Denosumab and bisphosphonates: different mechanisms of action and effects. Bone 48: 677-692.

50. Ebetino FH, Hogan AM, Sun S, Tsoumpra MK, Duan X, et al. (2011) The relationship between the chemistry and biological activity of the bisphosphonates. Bone 49: 20-33.

51. Albrektsson T, Zarb G, Worthington P, Eriksson AR (1986) The long-term efficacy of currently used dental implants: a review and proposed criteria of success. Int J Oral Maxillofac Implants 1: 11-25.

52. Marx RE, Garg AK (1998) Bone structure, metabolism, and physiology: its impact on dental implantology. Implant Dent 7: 267-276.

53. Zaidi M, Blair HC, Moonga BS, Abe E, Huang CL (2003) Osteoclastogenesis bone resorption, and osteoclast-based therapeutics. J Bone Miner Res 18 : 599-609.

54. Zaidi M (2007) Skeletal remodeling in health and disease. Nat Med 13: 791-801.

55. Lang NP, Salvi GE, Huynh-Ba G, Ivanovski S, Donos N, et al. (2011) Early osseointegration to hydrophilic and hydrophobic implant surfaces in humans. Clin Oral Implants Res 22(4): 349-56. 
Citation: Ballantyne E (2015) "Bisphosphonates: Possible Modes of Action and Implications for Dental Implant Treatment. A Review of the Literature". J Gen Pract 3: 192. doi:10.4172/2329-9126.1000192

Page 26 of 28

56. Fleisch H, Russell RG, Straumann F (1966) Effect of pyrophosphate on hydroxyapatite and its implications in calcium homeostasis. Nature 212: 901-903.

57. Santini D, Vespasiani Gentilucci U, Vincenzi B, Picardi A, Vasaturo F, et al. (2003) The antineoplastic role of bisphosphonates: from basic research to clinical evidence. Ann Oncol 14: 1468-1476.

58. Roelofs AJ, Thompson K, Ebetino FH, Rogers MJ, Coxon FP (2010) Bisphosphonates: molecular mechanisms of action and effects on bone cells monocytes and macrophages. Curr Pharm Des 16: 2950-2960.

59. Russell RG, Rogers MJ, Frith JC, Luckman SP, Coxon FP, et al. (1999) The pharmacology of bisphosphonates and new insights into their mechanisms of action. J Bone Miner Res 14 Suppl 2: 53-65.

60. Russell RG, Xia Z, Dunford JE, Oppermann U, Kwaasi A, et al. (2007) Bisphosphonates: an update on mechanisms of action and how these relate to clinical efficacy. Ann N Y Acad Sci 1117: 209-257.

61. Dominguez LJ, Di Bella G, Belvedere M, Barbagallo M (2011) Physiology of the aging bone and mechanisms of action of bisphosphonates. Biogerontology 12: $397-408$

62. Ikebe T. (2013) Pathophysiology of BRONJ: Drug-related osteoclastic disease of the jaw. Oral Science International 10(1): 1-8.

63. Marx R (2007) Oral and Intravenous Bisphosphonate-Induced Osteonecrosis of the Jaws: History, Eitiology, Prevention and Treatment. Chicago, Berlin, Tokyo, London, Paris, Milan, Barcelona, Istanbul, Sao Paulo, Mumbai, Moscow, Prague, Warsaw, Quintessence Publishing Co, Inc.

64. Russell RG, Rogers MJ (1999) Bisphosphonates: from the laboratory to the clinic and back again. Bone 25: 97-106.

65. Fleisch HA (1997) Bisphosphonates: preclinical aspects and use in osteoporosis. Ann Med 29: 55-62.

66. Bourgeois SL Jr (2009) Bisphosphonate medications--the good, the bad, and the ugly. Tex Dent J 126: 596-604.

67. Ruggiero SL, Drew SJ (2007) Osteonecrosis of the jaws and bisphosphonate therapy. J Dent Res 86: 1013-1021.

68. Ruggiero SL, Mehrotra B (2009) Bisphosphonate-related osteonecrosis of the jaw: diagnosis, prevention, and management. Annu Rev Med 60: 85-96.

69. Koka S, Salinas TJ, Kennel KA (2009) Osteoporosis, fracture risk, and prosthodontic implications. Int J Prosthodont 22: 505-506.

70. Giger EV, Castagner B, Leroux JC (2013) Biomedical applications of bisphosphonates. J Control Release 167: 175-188.

71. Mehrotra B (2009) Bisphosphonates--role in cancer therapies. J Oral Maxillofac Surg 67: 19-26.

72. Otomo-Corgel J (2007) Implants and oral bisphosphonates: risky business? J Periodontol 78: 373-376.

73. Otomo-Corgel J (2012) Osteoporosis and osteopenia: implications for periodontal and implant therapy. Periodontol 2000 59: 111-139.

74. Fleisch H (1981) Diphosphonates: history and mechanisms of action. Metab Bone Dis Relat Res 3: 279-287.

75. Rodan GA, Fleisch HA (1996) Bisphosphonates: mechanisms of action. J Clin Invest 97: 2692-2696.

76. Luckman SP, Hughes DE, Coxon FP, Graham R, Russell G, et al. (1998) Nitrogen-containing bisphosphonates inhibit the mevalonate pathway and prevent post-translational prenylation of GTP-binding proteins, including Ras. J Bone Miner Res 13(4): 581-9.

77. Reszka AA, Rodan GA (2003) Bisphosphonate mechanism of action. Curr Rheumatol Rep 5: 65-74.

78. Reszka AA, Rodan GA (2004) Nitrogen-containing bisphosphonate mechanism of action. Mini Rev Med Chem 4: 711-719.

79. Cheng A, Mavrokokki A, Carter G, Stein B, Fazzalari NL, et al. (2005) The dental implications of bisphosphonates and bone disease. Aust Dent J 50: S4-13.

80. Drake MT, Clarke BL, Khosla S (2008) Bisphosphonates: mechanism of action and role in clinical practice. Mayo Clin Proc 83: 1032-1045.

81. Li B, Ling Chau JF, Wang X, Leong WF (2011) Bisphosphonates, specific inhibitors of osteoclast function and a class of drugs for osteoporosis therapy. $J$ Cell Biochem 112: 1229-1242.
82. Bayliss L, Mahoney DJ, Monk, P. (2012) Normal bone physiology, remodelling and its hormonal regulation. Surgery 30(2): 47-53.

83. Walia M, Arora S, Singal B (2011) Oral Bisphosphonates and Dental Implants: A Review and Update. J Impl Adv Clin Dent 3(1): 83-87.

84. Amin D, Cornell SA, Gustafson SK, Needle SJ, Ullrich JW, et al. (1992) Bisphosphonates used for the treatment of bone disorders inhibit squalene synthase and cholesterol biosynthesis. J Lipid Res 33: 1657-1663.

85. Van Beek E, Lowik C, Van der PG, Papapoulos S. (1999) The role of geranylgeranylation in bone resorption and its suppression by bisphosphonates in fetal bone explants in vitro: A clue to the mechanism of action of nitrogencontaining bisphosphonates. J Bone Miner Res 14(5): 722-9.

86. Van Beek ER, Cohen LH, Leroy IM, Ebetino FH, Löwik CW, et al. (2003) Differentiating the mechanisms of antiresorptive action of nitrogen containing bisphosphonates. Bone 33: 805-811.

87. Fleisch H (2001) Zoledronic acid: an evolving role in the treatment of cancer patients with bone disease. Semin Oncol 28: 45-47.

88. Buhaescu I, Izzedine H (2007) Mevalonate pathway: a review of clinical and therapeutical implications. Clin Biochem 40: 575-584.

89. Itzstein C, Coxon FP, Rogers MJ (2011) The regulation of osteoclast function and bone resorption by small GTPases. Small GTPases 2: 117-130.

90. Theoleyre S, Wittrant Y, Tat SK, Fortun Y, Redini F, et al. (2004) The molecular triad OPG/RANK/RANKL: involvement in the orchestration of pathophysiological bone remodeling. Cytokine Growth Factor Rev 15: 457-475.

91. Bone HG, Adami S, Rizzoli R, Favus M, Ross PD, et al. (2000) Weekly administration of alendronate: rationale and plan for clinical assessment. Clin Ther 22: 15-28.

92. Bellido T, Plotkin LI (2011) Novel actions of bisphosphonates in bone preservation of osteoblast and osteocyte viability. Bone 49: 50-55.

93. McClung M, Harris ST, Miller PD, Bauer DC, Davison KS, et al. (2013) Bisphosphonate therapy for osteoporosis: benefits, risks, and drug holiday. Am J Med 126: 13-20.

94. Black DM, Reid IR, Boonen S, Bucci RC, Cauley JA, et al. (2012) The effect of 3 versus 6 years of zoledronic acid treatment of osteoporosis: a randomized extension to the HORIZON-Pivotal Fracture Trial (PFT). J Bone Miner Res 27(2): 243-54

95. Ro C, Cooper O (2013) Bisphosphonate drug holiday: choosing appropriate candidates. Curr Osteoporos Rep 11: 45-51.

96. Pazianas M, Epstein S, Zaidi M (2009) Evaluating the antifracture efficacy of bisphosphonates. Rev Recent Clin Trials 4: 122-130.

97. Allen MR, Burr DB (2011) Bisphosphonate effects on bone turnover, microdamage, and mechanical properties: what we think we know and what we know that we don't know. Bone 49: 56-65.

98. Otto S, Schreyer C, Hafner S, Mast G, Ehrenfeld M, et al. (2012)Bisphosphonaterelated osteonecrosis of the jaws - characteristics, risk factors, clinical features, localization and impact on oncological treatment. J Craniomaxillofac Surg 40 303-309.

99. Subramanian G, Fritton JC, lyer S, Quek SY (2012) Atypical dental implant failure with long-term bisphosphonate treatment--akin to atypical fractures? Oral Surg Oral Med Oral Pathol Oral Radiol 114: e30-35.

100. Cheng A, Daly CG, Logan RM, Stein B, Goss AN (2009) Alveolar bone and the bisphosphonates. Aust Dent J 54 Suppl 1: S51-61.

101. Mavrogenis AF, Dimitriou R, Parvizi J, Babis GC (2009) Biology of implant osseointegration. J Musculoskelet Neuronal Interact 9: 61-71.

102. Terheyden H, Lang NP, Bierbaum S, Stadlinger B (2012) Osseointegration-communication of cells. Clin Oral Implants Res 23: 1127-1135.

103. Villar C, Huynh-Ba G, Mills M, Cochran D. (2012) â€ Wound healing around dental implants. Endodontic Topics 25(1): 44-62.

104. Raisz LG (1999) Physiology and pathophysiology of bone remodeling. Clin Chem 45: 1353-1358.

105. Crockett JC, Rogers MJ, Coxon FP, Hocking LJ, Helfrich MH (2011) Bone remodelling at a glance. J Cell Sci 124: 991-998.

106. Hadjidakis DJ, Androulakis II (2006) Bone remodeling. Ann N Y Acad Sci 1092: 385-396. 
Citation: Ballantyne E (2015) "Bisphosphonates: Possible Modes of Action and Implications for Dental Implant Treatment. A Review of the Literature". J Gen Pract 3: 192. doi:10.4172/2329-9126.1000192

Page 27 of 28

107. Mellis DJ, Itzstein C, Helfrich $\mathrm{MH}$, Crockett JC (2011) The skeleton: a multifunctional complex organ: the role of key signalling pathways in osteoclast differentiation and in bone resorption. J Endocrinol 211: 131-143.

108. Lambrinoudaki I, Christodoulakos G, Botsis D (2006) Bisphosphonates. Ann N Y Acad Sci 1092: 397-402.

109. Cremers S, Garnero P (2006) Biochemical markers of bone turnover in the clinical development of drugs for osteoporosis and metastatic bone disease: potential uses and pitfalls. Drugs 66: 2031-2058.

110. Mönkkönen J, Koponen HM, Ylitalo P (1990) Comparison of the distribution of three bisphosphonates in mice. Pharmacol Toxicol 66: 294-298.

111. Gasser JA, Kneissel M, Thomsen JS, Mosekilde L (2000) PTH and interactions with bisphosphonates. J Musculoskelet Neuronal Interact 1: 53-56.

112. Zak M, Spina AM, Spinazze RP, Perkinson WL, Spinazze DJ (2007) Bisphosphonates and the dental patient: part 1. Compend Contin Educ Dent 28: 464-468.

113. Zak M, Spina AM, Spinazze RP, Perkinson WL, Spinazze DJ (2007) Bisphosphonates and the dental patient: Part 2. Compend Contin Educ Dent 28: 510-515.

114. Dixon RB, Tricker ND, Garetto LP (1997) Bone turnover in elderly canine mandible and tibia. J Dent Res 76: 336.

115. Allen MR (2007) Animal models of osteonecrosis of the jaw. J Musculoskelet Neuronal Interact 7: 358-360.

116. Reid IR (2009) Osteonecrosis of the jaw: who gets it, and why? Bone 44: 4-10.

117. Kim JH, Park YB, Li Z, Shim JS, Moon HS, et al. (2011) Effect of alendronate on healing of extraction sockets and healing around implants. Oral Dis 17: 705-711.

118. Kyrgidis A, Vahtsevanos K (2011) Bisphosphonate-related osteonecrosis of the jaws: a review of 34 cases and evaluation of risk. J Craniomaxillofac Surg 271.

119. Allam E, Allen M, Chu TM, Ghoneima A, Jack Windsor L (2011) In vivo effects of zoledronic acid on oral mucosal epithelial cells. Oral Dis 17: 291-297.

120.Pazianas M (2011) Osteonecrosis of the jaw and the role of macrophages. $J$ Natl Cancer Inst 103: 232-240.

121. Holzinger D, Seemann R, Klug C, Ewers R, Millesi G, et al. (2013) Longterm success of surgery in bisphosphonate-related osteonecrosis of the jaws (BRONJs). Oral Oncol 49: 66-70.

122. Ziebart T, Pabst A, Klein MO, Kammerer P, Gauss L, et al. (2011) Bisphosphonates: restrictions for vasculogenesis and angiogenesis: inhibition of cell function of endothelial progenitor cells and mature endothelial cells in vitro. Clin Oral Investig 15(1): 105-11

123. Borromeo GL, Tsao CE, Darby IB, Ebeling PR (2011) A review of the clinica implications of bisphosphonates in dentistry. Aust Dent J 56: 2-9.

124. Young, A , McNaught C. (2011) The physiology of wound healing. Surgery 29(10): 475-479.

125. Pazianas M, Abrahamsen B (2011) Safety of bisphosphonates. Bone 49: 103110.

126. Abrahamsen B (2010) Adverse effects of bisphosphonates. Calcif Tissue In 86: 421-435.

127. Liddelow G, Klineberg I (2011) Patient-related risk factors for implant therapy. A critique of pertinent literature. Aust Dent J 56: 417-426.

128. Walter C, Nawas B, WagnerW (2012) â€ The implications of bisphosphonate therapy for dental implant therapy. Forum Implantologicum 8(2): 94-102.

129. Subramanian G, Cohen HV, Quek SY (2011) A model for the pathogenesis of bisphosphonate-associated osteonecrosis of the jaw and teriparatide's potential role in its resolution. Oral Surg Oral Med Oral Pathol Oral Radio Endod 112: 744-753.

130.Bagán J, Blade J, Cozar JM, Constela M, García Sanz R, et al. (2007) Recommendations for the prevention, diagnosis, and treatment of osteonecrosis of the jaw (ONJ) in cancer patients treated with bisphosphonates. Med Oral Patol Oral Cir Bucal 12: E336-340.

131. Chaudhry AN, Ruggiero SL (2007) Osteonecrosis and bisphosphonates in ora and maxillofacial surgery. Oral Maxillofac Surg Clin North Am 19: 199-206, vi.
132. Khosla S, Burr D, Cauley J, Dempster DW, Ebeling PR, et al. (2007) Bisphosphonate-associated osteonecrosis of the jaw: report of a task force of the American Society for Bone and Mineral Research. J Bone Miner Res 22(10: 1479-91.

133. Assael L A. (2009) Oral Bisphosphonates as a Cause of BisphosphonateRelated Osteonecrosis of the Jaws: Clinical Findings, Assessment of Risks, and Preventive Strategies. Journal of Oral and Maxillofacial Surgery 67(5): 35-43.

134.Ruggiero SL (2009) Bisphosphonate-related osteonecrosis of the jaw (BRONJ): initial discovery and subsequent development. J Oral Maxillofac Surg 67: 13-18.

135. Chadha GK, Ahmadieh A, Kumar SK, Sedghizadeh PP (2012)'Osseointegration of dental implants and osteonecrosis of the jaw in patients treated with bisphosphonate therapy: A systematic review, J Oral Implantol.

136. Bagan J, Scully C, Sabater V, Jimenez Y (2009) Osteonecrosis of the jaws in patients treated with intravenous bisphosphonates (BRONJ): A concise update. Oral Oncol 45: 551-554.

137.Wang HL, Weber D, McCauley LK (2007) Effect of long-term ora bisphosphonates on implant wound healing: literature review and a case report. J Periodontol 78: 584-594.

138. Ruggiero SL (2011) Bisphosphonate-related osteonecrosis of the jaw: an overview. Ann N Y Acad Sci 1218: 38-46.

139. Garg AK (2006) Bisphosphonates and avascular necrosis of alveolar bone: a potential threat to dental implants. Dent Implantol Update 17: 73-78.

140. Kumar V, Pass B, Guttenberg SA, Ludlow J, Emery RW, et al. (2007) Bisphosphonate-related osteonecrosis of the jaws: a report of three cases demonstrating variability in outcomes and morbidity. J Am Dent Assoc 138 602-609.

141.Lam DK, Sándor GK, Holmes HI, Evans AW, Clokie CM (2007) A review of bisphosphonate-associated osteonecrosis of the jaws and its management. J Can Dent Assoc 73: 417-422.

142. Mariotti A (2008) Bisphosphonates and osteonecrosis of the jaws. J Dent Educ 72: 919-929.

143. Khan AA, Sandor GK, Dore E, Morrison AD, Alsahli M, et al. (2009) Bisphosphonate associated osteonecrosis of the jaw. J Rheumatol 478-90.

144. Lo JC, O'Ryan F, Yang J, Hararah MK, Gonzalez JR, et al. (2011) Oral health considerations in older women receiving oral bisphosphonate therapy. J Am Geriatr Soc 59: 916-922.

145. Lo JC, O'Ryan FS, Gordon NP, Yang J, Hui RL, et al. (2010) Prevalence of osteonecrosis of the jaw in patients with oral bisphosphonate exposure. $\mathrm{J}$ Oral Maxillofac Surg 68: 243-253.

146. Fleisher KE, Glickman RS (2011) Risk factors for bisphosphonate-related osteonecrosis of the jaws. J Oral Maxillofac Surg 69: 959.

147. Hoff AO, Toth B, Hu M, Hortobagyi GN, Gagel RF (2011) Epidemiology and risk factors for osteonecrosis of the jaw in cancer patients. Ann N Y Acad Sci 1218: 47-54.

148. Kühl S, Walter C, Acham S, Pfeffer R, Lambrecht JT (2012) Bisphosphonaterelated osteonecrosis of the jaws--a review. Oral Oncol 48: 938-947.

149. Levin L, Laviv A, Schwartz-Arad D (2007) Denture-related osteonecrosis of the maxilla associated with oral bisphosphonate treatment. J Am Dent Assoc 138: $1218-1220$.

150. Hoff AO, Toth BB, Altundag K, Johnson MM, Warneke CL, et al. (2008) Frequency and risk factors associated with osteonecrosis of the jaw in cancer patients treated with intravenous bisphosphonate. J Bone Miner Res 23(6): 826-36.

151. Markiewicz MR, Margarone JE 3rd, Campbell JH, Aguirre A (2005) Bisphosphonate-associated osteonecrosis of the jaws: a review of current knowledge. J Am Dent Assoc 136: 1669-1674.

152. Sarasquete ME, González M, San Miguel JF, García-Sanz R (2009) Bisphosphonate-related osteonecrosis: genetic and acquired risk factors. Oral Dis 15: 382-387.

153.Zadik Y, Abu-Tair J, Yarom N, Zaharia B, Elad S (2012) The importance of a thorough medical and pharmacological history before dental implant placement. Aust Dent J 57: 388-392.

154. Favia G, Pilolli GP Maiorano E (2009) Histologic and histomorphometric features of bisphosphonate-related osteonecrosis of the jaws: an analysis of 31 cases with confocal laser scanning microscopy. Bone 406-13. 
155. Fantasia JE (2009) Bisphosphonates--what the dentist needs to know: practical considerations. J Oral Maxillofac Surg 67: 53-60.

156. Kassolis JD, Scheper M, Jham B, Reynolds MA (2010) Histopathologic findings in bone from edentulous alveolar ridges: a role in osteonecrosis of the jaws? Bone 47: 127-130.

157. Kramer J, Fantasia J (2011) Bisphosphonates and Osteonecrosis of the Jaws: A Review of Clinical Features and the Drug Effect on Oral Soft Tissues. Clinic Rev Bone Miner Metab 9: 38-46.

158. McLeod NM, Brennan PA, Ruggiero SL (2012) Bisphosphonate osteonecrosis of the jaw: a historical and contemporary review. Surgeon 10: 36-42.

159. Marx RE , Tursun R (2012) Suppurative osteomyelitis, bisphosphonate induced osteonecrosis, osteoradionecrosis: a blinded histopathologic comparison and its implications for the mechanism of each disease. Int J Ora Maxillofac Surg 283-9.

160. Kwon YD, Ohe JY, Kim DY, Chung DJ, Park YD (2011) Retrospective study of two biochemical markers for the risk assessment of oral bisphosphonaterelated osteonecrosis of the jaws: can they be utilized as risk markers? Clin Oral Implants Res 22: 100-105.

161. Naik NH, Russo TA (2009) Bisphosphonate-related osteonecrosis of the jaw: the role of actinomyces. Clin Infect Dis 49: 1729-1732.

162. Yuan K, Chen KC, Chan YJ, Tsai CC, Chen HH, et al. (2012) Dental implant failure associated with bacterial infection and long-term bisphosphonate usage: a case report. Implant Dent 21: 3-7.

163. Shirota T, Nakamura A, Matsui Y, Hatori M, Nakamura M, et al. (2009) Bisphosphonate-related osteonecrosis of the jaw around dental implants in the maxilla: report of a case. Clin Oral Implants Res 20: 1402-1408.

164. Lazarovici TS, Yahalom R, Taicher S, Schwartz-Arad D, Peleg O, et al. (2010) Bisphosphonate-related osteonecrosis of the jaw associated with dental implants. J Oral Maxillofac Surg 68: 790-796.

165. Favia G, Piattelli A, Sportelli P, Capodiferro S, lezzi G (2011) Osteonecrosis of the posterior mandible after implant insertion: a clinical and histological case report. Clin Implant Dent Relat Res 13: 58-63.

166. Stanford CM (2010) Surface modification of biomedical and dental implants and the processes of inflammation, wound healing and bone formation. Int $\mathrm{J}$ Mol Sci 11: 354-369.

167. Jung RE, Pjetursson BE, Glauser R, Zembic A, Zwahlen M, et al. (2008) A systematic review of the 5 -year survival and complication rates of implantsupported single crowns. Clin Oral Implants Res 19: 119-130.

168. Roos-Jansåker AM, Lindahl C, Renvert H, Renvert S (2006) Nine- to fourteenyear follow-up of implant treatment. Part I: implant loss and associations to various factors. J Clin Periodontol 33: 283-289.

169. Misch CE, Perel ML, Wang HL, Sammartino G, Galindo-Moreno P, et al. (2008) Implant success, survival, and failure: the International Congress of Oral Implantologists (ICOI) Pisa Consensus Conference. Implant Dent 5-15.

170.Serra MP, Llorca CS, Donat FJ (2008) Oral implants in patients receiving bisphosphonates: a review and update. Med Oral Patol Oral Cir Bucal 13 E755-760.

171. Wynn RL (2008) Do Fosamax-type drugs increase the risk of osteonecrosis of the jaw for patients receiving dental implants? Gen Dent 56: 410-411.

172. Aspenberg P (2009) Bisphosphonates and implants: an overview. Acta Orthop 80: $119-123$.

173. Flichy-Fernández AJ, Balaguer-Martínez J, Peñarrocha-Diago $M$, Bagán JV (2009) Bisphosphonates and dental implants: current problems. Med Ora Patol Oral Cir Bucal 14: E355-360.

174. McLeod NM (2009) Oral bisphosphonates and dental implants. J Oral Maxillofac Surg 67: 1355.

175. Mellado-Valero A, Ferrer-García JC, Calvo-Catalá J, Labaig-Rueda C (2010) Implant treatment in patients with osteoporosis. Med Oral Patol Oral Cir Bucal 15: e52-57.

176. Montoya-Carralero JM, Parra-Mino $P$, Ramírez-Fernández $P$, Morata-Murcia IM, Mompeán-Gambín Mdel C, et al. (2010) Dental implants in patients treated with oral bisphosphonates: a bibliographic review. Med Oral Patol Oral Cir Bucal 15: e65-69.

177. Ferlito S, Liardo C, Puzzo S (2011) Bisphosponates and dental implants: a case report and a brief review of literature. Minerva Stomatol 60: 75-81.
178. Kim RH, Lee RS, Williams D, Bae S, Woo J et al. (2011) Bisphosphonates induce senescence in normal human oral keratinocytes. J Dent Res 90: 810-816.

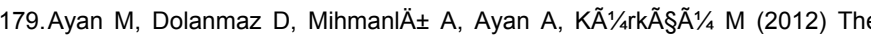
effect of systemically administrated zoledronic acid on the osseointegration of dental implants. Oral Dis 18: 802-808.

180. Jacobsen C, Metzler P, Rössle M, Obwegeser J, Zemann W, et al. (2013) Osteopathology induced by bisphosphonates and dental implants: clinical observations. Clin Oral Investig 17: 167-175.

181. Fugazzotto PA, Lightfoot WS, Jaffin R, Kumar A (2007) Implant placement with or without simultaneous tooth extraction in patients taking ora bisphosphonates: postoperative healing, early follow-up, and the incidence of complications in two private practices. J Periodontol 78: 1664-1669.

182.Bell BM, Bell RE (2008) Oral bisphosphonates and dental implants: a retrospective study. J Oral Maxillofac Surg 66: 1022-1024.

183. Grant BT, Amenedo C, Freeman K, Kraut RA (2008) Outcomes of placing dental implants in patients taking oral bisphosphonates: a review of 115 cases. J Oral Maxillofac Surg 66: 223-230.

184. Koka S, Babu NM, Norell A (2010) Survival of dental implants in postmenopausal bisphosphonate users. J Prosthodont Res 54: 108-111.

185. Starck WJ, Epker BN (1995) Failure of osseointegrated dental implants after diphosphonate therapy for osteoporosis: a case report. Int J Oral Maxillofac Implants 10: 74-78.

186. Brooks JK, Gilson AJ, Sindler AJ, Ashman SG, Schwartz KG, et al. (2007) Osteonecrosis of the jaws associated with use of risedronate: report of 2 new cases. Oral Surg Oral Med Oral Pathol Oral Radiol Endod 103: 780-786.

187. McLeod NM, Patel V, Kusanale A, Rogers SN, Brennan PA. (2011) Bisphosphonate osteonecrosis of the jaw: a literature review of UK policies versus international policies on the management of bisphosphonate osteonecrosis of the jaw. Br J Oral Maxillofac Surg 335-42.

188. Saldanha S, Shenoy VK, Eachampati P, Uppal N (2012) Dental implications of bisphophonate-related osteonecrosis. Gerodontology 29: 177-187.

189. Edwards BJ, Hellstein JW, Jacobsen PL, Kaltman S, Mariotti A, et al. (2008) Updated recommendations for managing the care of patients receiving ora bisphosphonate therapy: an advisory statement from the American Dental Association Council on Scientific Affairs. J Am Dent Assoc 1674-7.

190. Nase JB, Suzuki JB (2006) Osteonecrosis of the jaw and oral bisphosphonate treatment. J Am Dent Assoc 137: 1115-1119.

191.Ruggiero SL, Woo SB (2008) Biophosphonate-related osteonecrosis of the jaws. Dent Clin North Am 52: 111-128, ix.

192.Rustemeyer J and Bremerich A (2010) Bisphosphonate-associated osteonecrosis of the jaw: what do we currently know? A survey of knowledge given in the recent literature. Clin Oral Investig 14(1): 59-64.

193. Shannon J, Shannon J, Modelevsky S, Grippo AA (2011) Bisphosphonates and osteonecrosis of the jaw. J Am Geriatr Soc 59: 2350-2355.

194. O'Ryan FS, Lo JC (2012) Bisphosphonate-related osteonecrosis of the jaw in patients with oral bisphosphonate exposure: clinical course and outcomes. J Oral Maxillofac Surg 70: 1844-1853.

195. Woo SB, Kalmar JR (2007) Osteonecrosis of the jaws and bisphosphonates Alpha Omegan 100: 194-202.

196. Patel V, McLeod NM, Rogers SN, Brennan PA (2011) Bisphosphonate osteonecrosis of the jaw--a literature review of UK policies versus international policies on bisphosphonates, risk factors and prevention. $\mathrm{Br} \mathrm{J}$ Oral Maxillofac Surg 251-7.

197. Abtahi J, Tengvall P, Aspenberg P (2012) A bisphosphonate-coating improves the fixation of metal implants in human bone. A randomized trial of dental implants. Bone 50: 1148-1151.

198. Berardi D, Carlesi T, Rossi F, Calderini M, Volpi R, et al. (2007) Potential applications of biphosphonates in dental surgical implants. Int J Immunopatho Pharmacol 20: 455-465

199. Papaspyridakos P, Chen CJ, Singh M, Weber HP, Gallucci GO (2012) Success criteria in implant dentistry: a systematic review. J Dent Res 91: 242-248.

200. Heufelder MJ, Hendricks J, Remmerbach T, Frerich B, Hemprich A, et al. (2012) Principles of oral surgery for prevention of bisphosphonate-related osteonecrosis of the jaw. Oral Surg Oral Med Oral Pathol Oral Radiol. 